\title{
Aportaciones al estudio arqueológico del mudéjar en la Alpujarra: las iglesias de planta de cajón
}

\section{Contributions to the archaeological study of Mudejar architecture in the Alpujarra region: the hall-like plan churches}

\author{
Antonio Montes Rivas \\ Centro de Estudios de Arqueología Bastetana (CEAB), Baza, Granada \\ e-mail: amontesrivas@gmail.com \\ Alejandro Pérez Ordóñez \\ Laboratorio de Arqueología y Arquitectura de la Ciudad (LAAC), Granada \\ e-mail: alexpintor@gmail.com
}

\section{RESUMEN}

En este artículo se aborda el estudio de los restos emergentes de varias iglesias mudéjares en la comarca de la Alpujarra. A través del análisis arqueológico de paramentos llevado a cabo, así como del examen de las fuentes escritas y el análisis del contexto urbanístico y territorial, se han caracterizado las iglesias de planta de cajón como una tipología propia del mudéjar alpujarreño. A la vez se ha mejorado el conocimiento tanto de la implantación parroquial en este medio rural del antiguo Reino nazarí de Granada, ya en época cristiana, como de la historia de los edificios que evolucionaron a la par que su territorio.

Palabras clave: Arquitectura mudéjar; técnicas y materiales constructivos; estudios murarios; Granada (provincia); Almería (provincia); siglo XVI.

\section{ABSTRACT}

This study approaches the standing remains of several Mudejar churches in the Alpujarra region. By means of the archaeological analysis of its walls, the revision of those related written sources and the study of its urban and territorial context, the hall-like plan churches are characterized as a singular typology of this region. This work has made possible as well to improve the knowledge of the parish introduction in the rural area of the Nasrid kingdom in Granada in the Christian period and of those buildings in use during that period in the region.

Keywords: Mudejar Architecture, building techniques and materials, standing walls recording, province of Granada, province of Almería, 16th century.

Recibido: 29 abril 2014. Aceptado: 26 agosto 2014.

\section{Copyright}

(c) 2014 CSIC. Este es un artículo de acceso abierto distribuido bajo los términos de la licencia Creative Commons Attribution-Non Commercial (by-nc) Spain 3.0. 


\section{INTRODUCCIÓN}

\section{Objetivos y planteamientos iniciales del estudio}

El objeto del presente trabajo es el estudio de un conjunto de iglesias en la Alpujarra que se pueden identificar entre las más antiguas de las conservadas en esta comarca, pero nuestros objetivos y planteamientos han sufrido una evolución desde que iniciamos la investigación hasta esta publicación. Nuestra primera toma de contacto fueron unas dudosas referencias a un supuesto «edificio antiguo», a veces calificado como «obra de romanos» ${ }^{1}$, otras «iglesia visigoda» ${ }^{2}$ e incluso como edificio «sin duda musulmán $»^{3}$, que nos hicieron aproximarnos a la aldea de Capilerilla (Granada) con gran curiosidad. Allí encontramos un edificio en ruinas del que hicimos una primera documentación gráfica y un análisis arqueológico de los restos emergentes, que nos llevó a caracterizarlo como una iglesia mudéjar. La necesidad de trazar paralelos con otros edificios para apoyar nuestras observaciones y reflexiones, en combinación con la investigación en las fuentes documentales y la bibliografía al respecto, escasa, dispersa y no siempre enfocada sobre los aspectos que nos interesaban de estos edificios, nos animaron a continuar abordando el tema hasta hacer un rastreo, no exhaustivo, pero sí suficientemente significativo, del territorio alpujarreño en busca de los rasgos característicos de este conjunto de edificios. Las primeras iglesias alpujarreñas tienen un gran interés para la comprensión de la implantación de la cultura cristiana impuesta por los conquistadores castellanos a la población islámica de la zona, inicialmente protegida por las Capitulaciones de 1491, pero presionada para su conversión tras la rebelión de 1500-15014, es decir, toda la problemática de los moriscos, de la que existe un prolijo tratamiento historiográfico pero a la que tal vez aún no se ha realizado un suficiente acercamiento desde el punto de vista de la cultura material.

\section{Metodología}

En conjunto, nuestro proceso de trabajo se ha configurado como una prospección, según un modelo que presenta algunos aspectos convergentes con la propuesta metodológica de Leandro Sánchez Zufiaurre en sus estudios

\footnotetext{
1 López de Vargas 1990: 188.

2 Carrascosa 1960: 244

3 Spahni 2010: 48-49.

4 Galán 1991.
}

del prerrománico en la Diócesis de Vitoria ${ }^{5}$, si bien realizamos únicamente el análisis de planta y técnicas constructivas de un número limitado de edificios. Para fijar unos límites razonables a este trabajo, debíamos ser selectivos en los ejemplos a tratar. Estudiamos un conjunto de iglesias en cuanto a tres aspectos fundamentales: el diseño de sus plantas, los materiales y técnicas constructivas empleados y la ubicación urbanística y territorial de estos edificios. Asimismo, en lo geográfico nos hemos ceñido a la comarca de la Alpujarra, extendida entre las provincias de Granada y Almería, si bien en otras zonas limítrofes se pueden encontrar edificios con características similares creados en un contexto sociohistórico también parecido. Igualmente, dentro de la Alpujarra existe un elevado número de iglesias que tienen elementos en común con las estudiadas, pero decidimos elegir exclusivamente un grupo que fuese suficientemente homogéneo en sus características y que presentase las menores modificaciones posibles respecto al modelo o proyecto original. Así, hablamos de una tipología de planta de iglesias de cajón, que presentan una única nave rectangular, originalmente cubierta con techumbres de madera de tradición artesanal mudéjar, que a veces tienen una capilla mayor cuadrada diferenciada del resto de la nave por pilastras y un arco toral, y con una torre-campanario de planta cuadrada adosada generalmente en un lateral, con clara influencia de los alminares de las mezquitas preexistentes en estas localidades, que están entre las que han contado con población musulmana durante un periodo más largo en la península Ibérica medieval y moderna. Las técnicas constructivas que hemos documentado para este modelo de iglesias, de estructura muy simple, son casi exclusivamente la mampostería de esquisto o caliza para la mayor parte de los muros, así como el ladrillo y la sillería para determinados elementos de refuerzo y ornamentales.

Partiendo de estas premisas, los ejemplos elegidos debían ser los más representativos del modelo planteado y presentar el menor número posible de alteraciones. En ese sentido, Capilerilla era un caso muy limitado por su estado de ruina y el gran expolio sufrido a lo largo de su historia. Otro ejemplo muy claro que resume todas las características que debió presentar Capilerilla pero con mayor conservación de sus alzados es la iglesia del despoblado de Iniza (Almería), que quedó abandonado desde la rebelión morisca de 1568, de modo que muestra

\footnotetext{
5 Sánchez Zufiaurre 2007.
} 


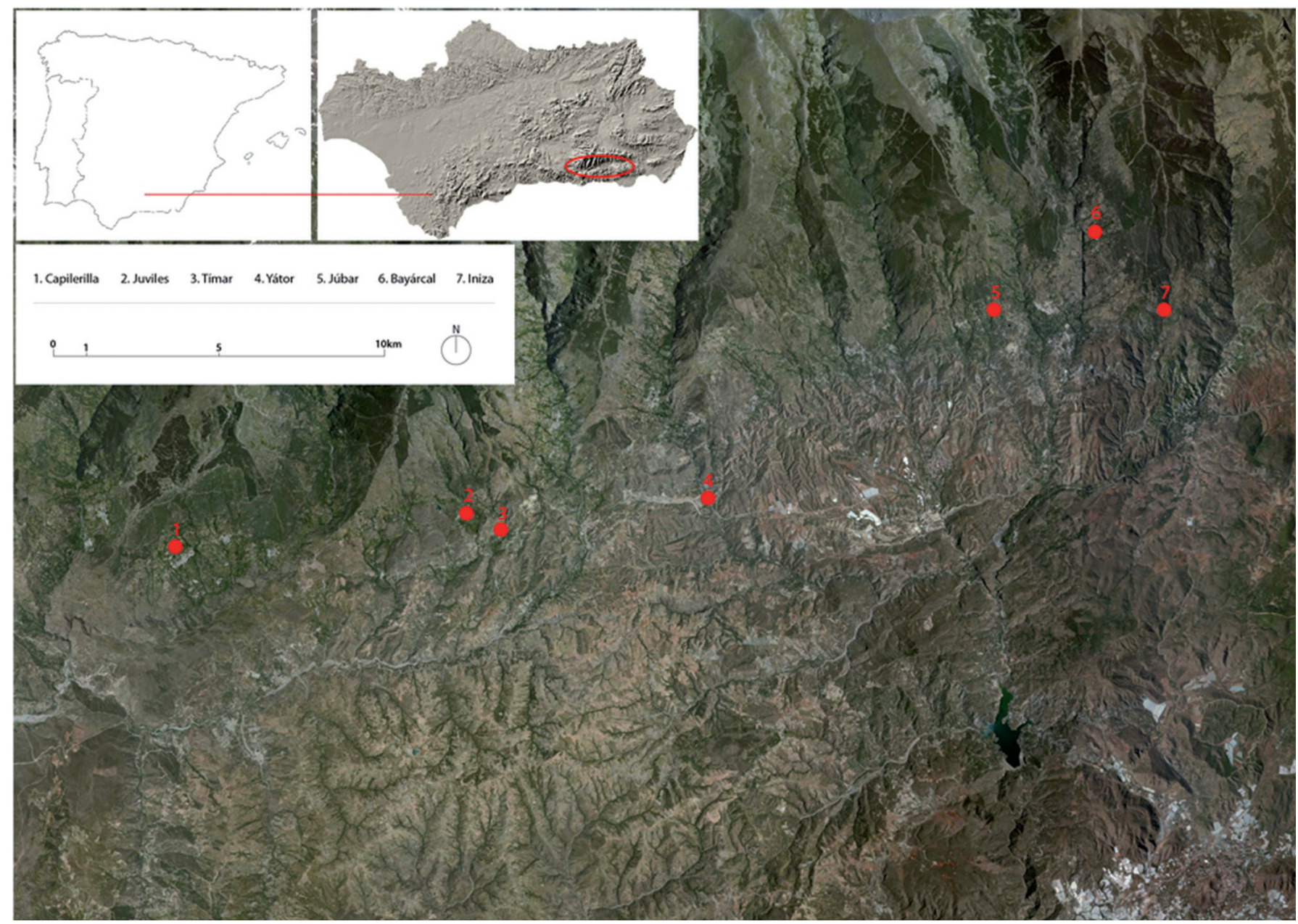

Fig. 1: Mapa general de situación de las iglesias estudiadas. Elaboración propia a partir de Ortofotografía (fuente: OGC).

a día de hoy una imagen más completa de lo que debieron ser estos templos. Otras iglesias aquí documentadas siguen en uso, pero dado que se encuentran ubicadas en núcleos de población cuya demografía y urbanismo en líneas generales no parecen haber sufrido grandes cambios desde la Edad Media, las intervenciones en las fábricas no las han desfigurado demasiado y son fácilmente identificables en una lectura diacrónica de la estratigrafía muraria de los edificios. Nos referimos a iglesias como la de Bayárcal (Almería) o la de Júbar (Granada). Finalmente, otros edificios elegidos muestran alguna ampliación del proyecto original como fue frecuente ya a lo largo de los siglos posteriores al XVI, consistiendo a veces en la ampliación volumétrica de la capilla mayor, caso de Juviles (Granada), o la modificación de los accesos, abriendo nuevas puertas y tapiando las antiguas, como se aprecia en Yátor (Granada). Un caso significativo puede ser el de Tímar (Granada), donde se dio una reducción sustancial de la planta original, acortando el templo por los pies. También se llegó a la sustitución de la iglesia, ya totalmente arruinada y expoliada, por una mínima ermita sobre una pequeña parte de su superficie original, como hoy vemos en Capilerilla. La ubicación geográfica de los ejemplos elegidos tampoco es baladí, tratando de abarcar un amplio territorio de esta extensa comarca y estudiando iglesias situadas en las dos provincias en las que hoy se divide administrativamente (Fig. 1).

Tras la selección de los casos a tratar, se acometió el estudio directo de la realidad construida de éstos: documentación de sus técnicas constructivas y materiales de construcción, análisis mensiocronológico de los mismos, identificación de elementos constructivos que lo componen, análisis de la planta y organización de los espacios, así como el examen posterior del contexto espacial donde se enmarca el edificio, en busca de analogías a nivel técnico, material, etc., junto a su encuadre urbanístico y territorial. Con todo ello se elaboró una documentación básica a nivel de plantas y técnicas constructivas, confeccionando un corpus que ha permitido 
realizar ciertas comparativas y cotejar datos entre ellas, proceso cuyos resultados son presentados en este artícu1o, interrelacionando los datos obtenidos en los diversos casos de estudio de manera sintética e integradora, extrayendo conclusiones generales para todos o la mayor parte de ellos e identificando también las variantes y elementos divergentes o de carácter excepcional.

\section{Los trabajos pioneros sobre el tema: Gómez-Moreno Calera y Cressier}

Algunos interesantes trabajos han abordado el estudio de las iglesias de esta región desde una perspectiva documental y arqueológica. Para una comprensión de esta temática abordada desde el estudio de las fuentes documentales, son esenciales las publicaciones de Gómez-Moreno Calera ${ }^{6}$ y Sánchez Real ${ }^{7}$. En las investigaciones arqueológicas, destaca la llevada a cabo por Cressier, quien en el transcurso de un estudio de paisaje en la transición de la Edad Media a la Moderna en la Alpujarra $^{8}$ realizó un acercamiento a algunas de las iglesias construidas tras la conquista castellana en esta zona, analizando sus técnicas constructivas, plantas, materiales, etc. Si bien los resultados de su investigación han sido ya superados o puntualizados, la metodología de estudio arquitectónico y material empleada por el autor se revela como esencial para entender la arquitectura mudéjar como un modo de trabajo con fuerte carácter gremial, de amplia extensión y relacionado con las «técnicas de albañil»». El estudio de esta particular arquitectura, abordado desde las fuentes escritas y el análisis paramental (técnicas, materiales, etc.), profundiza más allá de su fábrica y nos permite tomar el pulso cultural al siglo XVI granadino en un ámbito rural de gran particularidad.

\section{EL CONTEXTO}

\section{Aproximación geográfica e histórica: la Alpujarra}

La Alpujarra, configurada como una extensa zona montañosa entre las provincias de Granada y Almería, se presenta como un amplio valle que engloba las cuencas de los ríos Guadalfeo y Andarax, y que está formada por el conjunto meridional de laderas de Sierra Nevada y las tres sierras litorales que bordean la costa: Lújar,

\footnotetext{
6 Gómez-Moreno Calera 1987, 1989 b y 2004

7 Sánchez Real 2000.

8 Cressier 1988.

9 Quirós 1998: 236.
}

Contraviesa y Gádor. Esta geografía tan accidentada se ha comportado históricamente como una unidad cerrada a influencias externas, originando una región de fuerte personalidad y un tanto aislada, que ha llegado a desarrollar cierta singularidad en diversos aspectos socioculturales.

Se trata de una zona que ha sido habitada desde época prehistórica y que ha mantenido cierta continuidad en el poblamiento antiguo y medieval. Será sobre todo en este último periodo, en época nazarí, cuando alcance cierto auge económico y revelando una mayor presencia en las fuentes documentales. La toma de Granada por los Reyes Católicos en 1492 va a provocar una transformación, a diversos niveles, en esta región; unos procesos de cambio que son rastreables a lo largo del siglo XVI, además de esenciales para la comprensión histórica de este territorio en un momento clave como es el tránsito de la cultura islámica a la cristiana, en el escenario de paso de la Edad Media a la Modernidad.

\section{La Alpujarra nazarí: un contexto islámico en transición. Aproximación al urbanismo de sus núcleos de población}

Uno de los aspectos que nos interesa evaluar es la implantación de estas iglesias en un contexto urbanístico. Existe una serie de rasgos interpretados como específicamente característicos del urbanismo alpujarreño, en gran parte de origen medieval. Lo más habitual es que los pueblos alpujarreños se dividan en varios barrios, esto es, núcleos compactos con relativa separación entre ellos mediante espacios intersticiales ocupados generalmente por huertos, con caminos o calles que los cruzan y conectan los grupos de casas, como vienen documentando diversos investigadores ${ }^{10}$.

Estos barrios suelen contar con un nombre propio que los identifica desde la Edad Media en muchos casos, pues en la documentación histórica, por ejemplo los libros de hábices, aparecen los topónimos de estos ba$\operatorname{rrios}^{11}$. Como muestra de ello, y refiriéndonos a la Taha de Ferreira ${ }^{12}$, Gómez-Moreno ${ }^{13}$ menciona que Pitres se distribuía en tres barrios: El Çijar o Çigar, Beneuz y Haratalayni, teniendo muy cerca las aldeas de Aylacár y

\footnotetext{
10 Gómez-Moreno 1951; Cressier 1983: 92-96; Trillo 1992.

11 Suelen identificarse con la voz árabe hara, y existe un estudio sobre el uso de este étimo como topónimo en el área de las Alpujarras (Martínez 1985: vol. 2, 481-494).

12 La taha o ta' $a$ hace referencia a la división político-administrativa nazarí, comprendiendo la taha de Ferreira los núcleos poblacionales de Pitres, Capilerilla, Aylacar, Atalbéitar, Ferreirola, Mecina, Mecinilla y Fondales.

13 Gómez-Moreno 1951: 25.
} 



Fig. 2: Planos de dos poblaciones representadas en el Catastro de Ensenada (1745-1756). A la izquierda, Mecina Fondales, con indicación de Mecina en la parte superior, Mecinilla un poco más abajo, quedando la iglesia en la parte central; en la parte inferior, Fondales. En la imagen de la derecha, representación de Bayárcal y su entorno más próximo. Se puede observar la división en varios barrios y la posición central de la iglesia. En la parte inferior, el templo del despoblado de Iniza, junto al «cerro del castillejo», actual Castillo de Paterna.

Capileyra; que Ferreyrola tenía como anejo a Haratalbeytar; que Meçina de Ferreyra tenía tres barrios, por poner sólo algunos ejemplos. También podemos referirnos al caso de Bayárcal, en la Taha de Andarax, dividido en varios barrios: Alolia (al-ulià, la más alta), Açufla (alsuflà, la más baja) y Abuleyhem, interpretados como el barrio alto, barrio bajo y el tercero separado a una cota más baja ${ }^{14}$. Aún siglos después, esta agrupación del poblamiento en barrios dispersos sigue siendo patente en la cartografía histórica (Fig. 2).

Además del refrendo de la documentación histórica, es fácil constatar que el urbanismo de muchos de estos pueblos se divide en varios barrios aunque éstos no aparezcan mencionados en la documentación archivística o no conserven topónimos antiguos. Se puede considerar que este poblamiento de carácter disperso sería la forma más primitiva de hábitat en el ámbito alpujarreño, y que la sucesiva ocupación de los espacios intersticiales entre los barrios ha sido el fenómeno que ha generado un urbanismo más compacto en las localidades que han ido concentrando la población en detrimento de otras en las que se ha mantenido la disposición dispersa o que incluso históricamente fueron quedando despoblados ${ }^{15}$.

\footnotetext{
14 Trillo 1990: 417-418.

15 Esta misma dinámica de evolución urbanística y territorial se puede apreciar en otras comarcas que contaron con población morisca, como el
}

A lo largo del siglo XVI, y más acusadamente desde el inicio de la repoblación en 1572, se ha ido produciendo un proceso de saturación urbana en los núcleos con condiciones más favorables para el poblamiento. Por el contrario, en las localidades peor comunicadas o con otro tipo de condicionantes, el crecimiento de la población y sus construcciones ha sido sustancialmente menor, quedando en muchos casos prácticamente fosilizado el núcleo de origen medieval, con escasas modificaciones del parcelario hasta nuestros días ${ }^{16}$. Este carácter polinuclear estaría basado, según investigadores como Cressier, en la organización de la sociedad andalusí por grupos tribales y familiares ${ }^{17}$.

Valle del Genal, en la Serranía de Ronda (Málaga), donde algunos pueblos como Júzcar o Parauta aún muestran claramente una relativa dispersión del hábitat y evidente división en dos o tres barrios (Téllez 2003: 217 y 227). Igualmente, en una comarca limítrofe con la Alpujarra granadina, el Valle de Lecrín, encontramos ejemplos de este modelo de implantación urbanística polinuclear, analizados en su tesis doctoral por M. ${ }^{a}$ Aurora Molina Fajardo (Molina Fajardo, M.A. 2012: El espacio rural granadino tras la conquista castellana: urbanismo y arquitectura con funciones residenciales del Valle de Lecrín en el siglo XVI, tesis doctoral inédita, Universidad de Granada, 90-93). Sobre los despoblados en la Alpujarra, podemos enumerar varios ejemplos: Aylacar, Alguazta, Albayar, Undurón, Turrillas, Inqueira, etc. (Cressier 1983: 96-100).

16 Seguimos en nuestro análisis del parcelario y la evolución urbana de estos núcleos las pautas metodológicas marcadas en sus investigaciones por Navarro y Jiménez (2007).

Cressier 1983: 94 

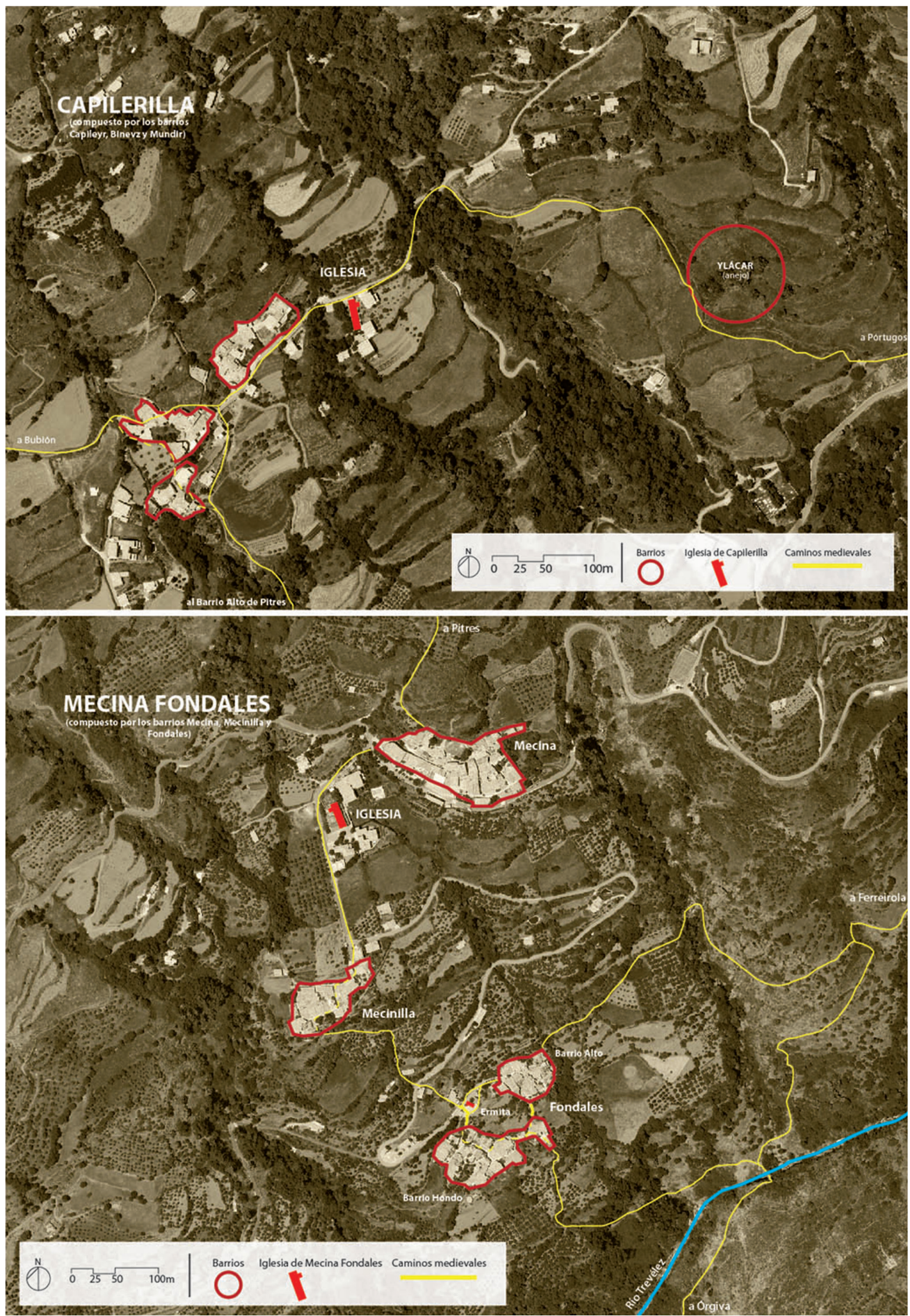

Fig. 3: Contexto urbanístico: planos de Capilerilla y Mecina Fondales con indicación de los barrios que los forman y la ubicación de las iglesias. Elaboración propia a partir de Ortofotografía (fuente: OGC). 

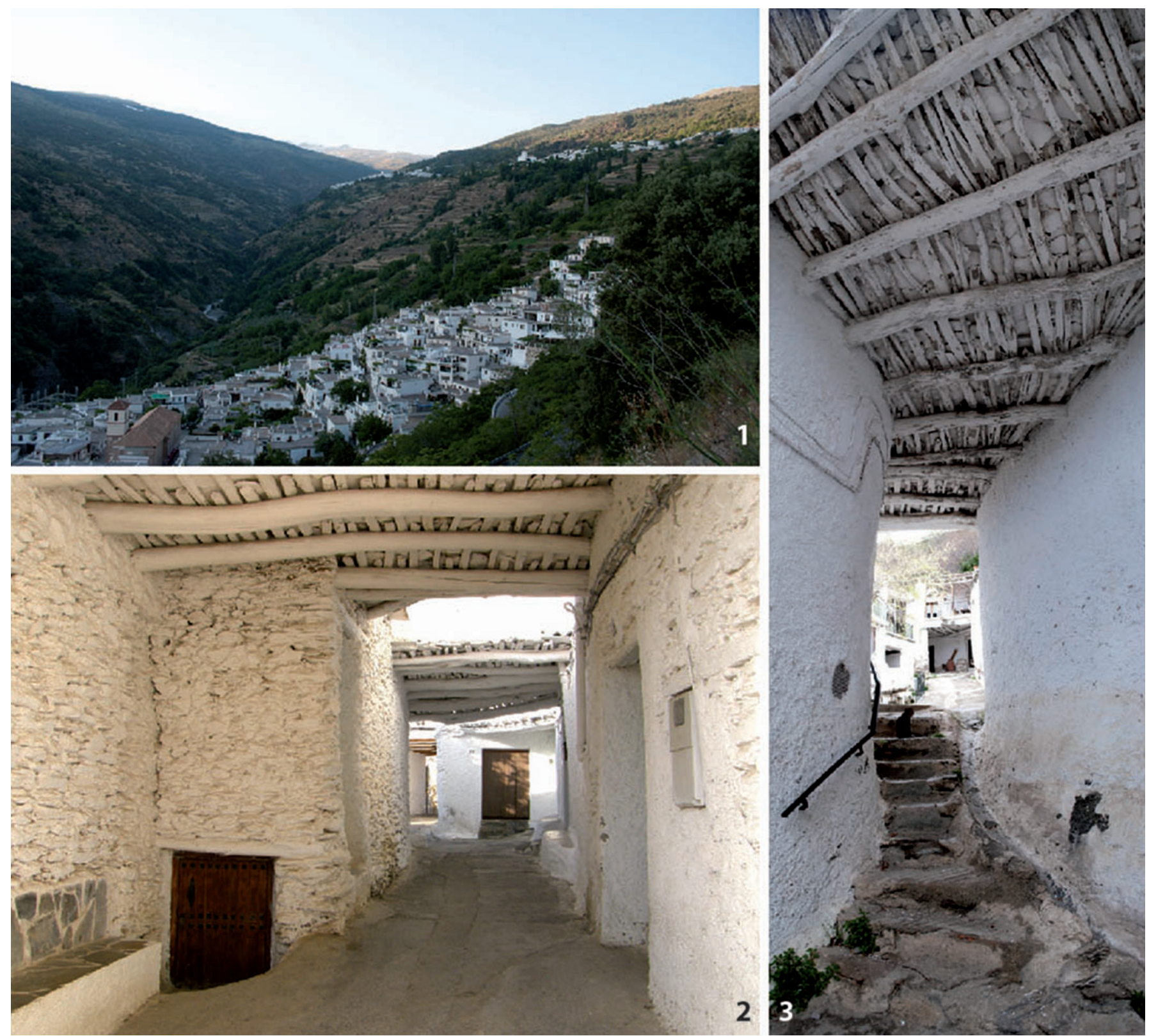

Fig. 4: Urbanismo alpujarreño: 1 - Vista de los núcleos del Barranco de Poqueira. En primer plano Pampaneira y a una cota superior, de derecha a izquierda, Bubión y Capileira. 2 - Tinaos en la calle Real de Capilerilla. 3 - Tinao en la calle Adarve de Atalbéitar.

Capilerilla puede considerarse como uno de estos ejemplos originarios del modelo de agrupación urbana característica de la Alpujarra (Fig. 3). Muestra un urbanismo de carácter disperso, dividido en al menos tres barrios (Capileyr, Mundir y Binevz), separados entre sí por zonas de huertas. Las casas, conectadas a través de tinaos (cobertizos), se adosan entre sí formando grupos y dejando entre ellos estrechas calles (Fig. 4). Los límites con los campos de cultivo están definidos tradicionalmente por albarradas de piedra y muros de contención (paratas), de trazados irregulares y muy adaptados al terreno y a su gran plasticidad, generalmente realizados en piedra seca con pequeñas lajas de esquisto.
Este modelo de urbanismo polinuclear se repite, aún en la actualidad, en pueblos como Mecina Fondales (fig. 3), dividido en Mecina (con los barrios de Harat Axehel y Harat Fedna), Fondales (con los barrios Azeuya y Harat Aben Ged) y Mecinilla, en medio de ambos y tal vez escindido de alguno de ellos ${ }^{18}$. También en Mecina Bombarón, Yegen y Juviles ${ }^{19}$, en los que se observa una pluralidad de núcleos de casas agrupadas, separados entre sí por espacios agrícolas más o menos amplios, y la iglesia

\footnotetext{
18 Trillo 1992: 83.

19 Cressier 1983: 95.
} 
siempre en una posición relativamente central. Estas formas urbanas reflejan la estructura de poblamiento nazarí bajomedieval, donde la alquería, con un asentamiento de carácter disperso, será la unidad de poblamiento esencial en la Alpujarra en este momento, y donde se producirá una serie de transformaciones con la llegada de los cristianos. La documentación castellana refleja a la perfección la composición esencial de este poblamiento rural nazarí, donde la mezquita (o la rábita en su defecto) se configura como elemento esencial dentro del aparato urbanístico, claramente definido en barrios separados entre sí.

\section{La erección parroquial en la Alpujarra en el siglo XVI}

Desde el momento de la conquista castellana, la Alpujarra se convirtió en un territorio eminentemente mudéjar, manteniendo dicho estatus hasta perderlo tras la revuelta protagonizada entre 1499-1501, donde se procederá al bautizo forzoso de la población rebelde. Este proceso de conversión masiva adquirió gran intensidad en los meses de verano de $1500^{20}$.

En este contexto de tensión social, adquirirá gran importancia el proceso de erección parroquial en la diócesis granadina, cuya génesis y evolución a lo largo del siglo XVI va a reflejar la implantación material de un modelo de ocupación y organización del territorio en una zona predominantemente morisca, de fuerte cohesión social y alta dispersión poblacional. Un proceso que se va a llevar a cabo mediante la transformación de los lugares de culto islámico en templos cristianos, primero con escasas modificaciones y, posteriormente, la construcción de nuevas iglesias, pasándose a amortizar las mezquitas y rábitas, como se detalla a continuación. En la Alpujarra, esto se llevará a cabo de manera desigual, y difícilmente llegará a tener homogeneidad, a pesar de los esfuerzos del arzobispado.

Una de las primeras fases de la erección parroquial alpujarreña se va a materializar mediante la transmutación de uno de los elementos más importantes de cohesión cultural islámica, como es la mezquita, en espacio de culto cristiano, reutilizándose sus estructuras, pero otorgándoles una nueva simbología y un nuevo contenido, en pro de comunicar el cambio de poder y facilitar así la adhesión del nuevo credo ${ }^{21}$. Los antiguos lugares de culto nazaríes, tanto mezquitas como rábitas, se van

\footnotetext{
20 Suberbiola 1987: 118.

21 El arabista Mikel de Epalza estudió la transformación de algunas mezquitas en iglesias y sus implicaciones urbanísticas (Epalza 1996).
}

a transformar en iglesias ${ }^{22}$ por medio de una serie de rituales de sacralización, tales como la aspersión de agua bendita, la colocación de un altar en el lado oriental, la destrucción del nicho del mihrab mediante la construcción de una puerta o su cegado, la colocación de una cruz en el alminar..., en definitiva, redefiniendo el espacio de culto y adaptándolo a los nuevos usos.

Se suplanta así la mezquita por la iglesia con una serie de reformas esenciales que buscan, en la mayoría de los casos, una solución de bajo coste para la dotación parroquial en las zonas rurales. También subyace un intento por parte de la Iglesia y la Corona de rápida aculturación de una población que hasta hace poco era nazarí, después fue brevemente mudéjar y ahora es morisca. Un proceso aculturador de urgencia que requirió la adopción de una serie de medidas pragmáticas ante la nueva situación social surgida.

De este período (1501) datará la adopción, por parte de la Iglesia, de la división administrativa nazarí (organizada en tahas) para la organización del partido alpujarreño ${ }^{23}$. En general, en estos primeros momentos apenas se construirán iglesias ${ }^{24}$, aprovechándose para ello los lugares de culto islámico (rábitas y mezquitas), ahora sacralizados para el ritual cristiano, pero en definitiva prácticamente inalterados. Una situación que corre paralela a lo ocurrido en otras zonas rurales del Reino de Granada. Así sucede en las comarcas de Guadix y Baza, donde la dotación parroquial se nutre en esencia de los edificios islámicos hasta el segundo tercio del siglo XVI, poco apropiados por sus reducidas dimensiones, pero bien situados y numerosos ${ }^{25}$.

En el caso alpujarreño existe un documento esencial para comprender hasta qué punto perviven las estructuras de culto nazaríes aún a finales del siglo XVI. Se trata de un informe que data de diciembre de 1578 y enero de 1579 , donde se relata la inspección realizada por el visita-

\footnotetext{
22 Por ser generalmente de menores dimensiones, es probable que algunas rábitas fuesen transformadas en ermitas, al menos en los núcleos donde existían otros edificios cultuales de mayor relevancia (sobre la extensión de mezquitas y rábitas, cf. Trillo 2011: 89), si bien en algunas alquerías la rábita había estado cumpliendo las funciones de mezquita aljama, como ocurría en un barrio de Válor (Gima Arrabita) y en Aylacar (Trillo 2011: 78).

23 Suberbiola 1987: 124 .

24 Las únicas iglesias terminadas en 1530 son las de Pitres, Tímar, Torvizcón, Ohanes, Laujar de Andarax, Dalías y Adra. Sin embargo, son algunas más las que por entonces empiezan ya a trazarse (Gómez-Moreno Calera 1989b: 189).

25 Así se describe en el transcurso de una visita al Marquesado del Zenete (1530), donde únicamente la iglesia de Dólar está construida, y añadiendo: «y que las otras siete Iglesias del dicho Marquesado del Cenete ninguna dellas estava hecha, sino como estavan mezquitas en tiempo de moros» (Espinar y Quesada 1995: 780).
} 
dor Alonso López de Carvajal, a las iglesias de la Alpujarra tras el levantamiento morisco de 1568. En él se señala la utilización de un gran número de «iglesias de las antiguas», una denominación que algunos autores afirman ser un claro indicador del uso y pervivencia de las mezquitas y rábitas, aún en fechas tan avanzadas (Busquístar, Poqueira, Carataunas, Cáñar, Bayacas, Bentarique, Yegen, etc. ${ }^{26}$. Más reveladores son en este sentido los datos recogidos en la visita pastoral del arzobispo Pedro de Castro ${ }^{27}$. En ella se detallan las modestas medidas y técnicas constructivas de algunas de estas mezquitas, ahora utilizadas como oratorios cristianos (Barge, Benizalte y Beires) ${ }^{28}$. Se trata de una situación que revela el desigual desarrollo del proceso de erección parroquial en el territorio alpujarreño en el siglo XVI, dándose indistintamente el uso de iglesias de nueva planta y la utilización de las antiguas mezquitas y rábitas transformadas para el culto.

El siguiente paso de la erección parroquial, ya superado el primer tercio de siglo, será la construcción de parroquias de nueva planta, siendo las Alpujarras una de las últimas comarcas en ser atendida, aunque la mejor dotada de la diócesis granadina (44 parroquias de las 97 totales $)^{29}$. Este dato no hace sino reforzar la imagen de una región mayoritariamente poblada por moriscos, aún arraigada a las costumbres y cultura islámicas, lo cual justificaría el considerable esfuerzo por parte de la Corona y la Iglesia por cristianizar este abrupto territorio.

No será hasta mediados del siglo XVI cuando se empiecen a construir iglesias de nueva planta con cierta continuidad. Un proceso que va a tomar nuevos bríos a merced del auge económico que experimenta Granada y de un mayor interés por parte del arzobispado. Estos nuevos espacios van a amortizar las antiguas mezquitas, sustituyéndolas en sus antiguos solares, ampliados estos por la compra de terrenos anexos ${ }^{30}$, o buscando nuevos espacios más diáfanos o en lugares estratégicos donde poder aglutinar los habitantes de varias parroquias. En este sentido, Cressier ha destacado el hecho de que generalmente en estos asentamientos polinucleares la iglesia vino a establecerse en un espacio ajeno a los diferentes barrios pero equidistante entre ellos, poniendo

\footnotetext{
26 Gómez-Moreno Calera 1987: 356-357.

27 Gómez-Moreno Calera 2004: 308.

28 En este sentido, únicamente el estudio de las fuentes ha permitido avanzar en un tema que resulta de gran interés, pero en el que las escasas intervenciones arqueológicas efectuadas en la Alpujarra no han podido ofrecer una visión más completa.

29 Suberbiola 1987: 124.

30 Sánchez Real 2000: 65.
}

como ejemplo el caso de Juviles ${ }^{31}$. Yegen y Mecina Bombarón $^{32}$ muestran también esta característica aún en nuestros días. Trillo ha puesto de manifiesto cómo ya desde época nazarí al menos se daba esta organización territorial, en la que varios barrios de una misma alquería o varias alquerías próximas entre sí compartían el uso de una mezquita aljama común, a veces en una ubicación geográfica aproximadamente central ${ }^{33}$.

En otras ocasiones cada núcleo se ha considerado un pueblo diferenciado de los próximos, a pesar de la escasa separación física en algunos casos, y aun así han tenido un templo de uso común. Se trata, por ejemplo, del antiguo municipio ${ }^{34}$ de Mecina Fondales, formado por los pueblos de Mecina y Mecinilla, prácticamente unidos por el punto donde se localiza la iglesia común a ambos, y Fondales en una posición geográfica a menor cota (Fig. 3). También sería el caso de Atalbéitar y Ferreirola, que si bien hoy en día tiene cada uno su propia iglesia, compartieron en un primer momento la denominada como Albáizar, que se localizaba en un pago rústico a medio camino de ambos pueblos. Observando el caso de Capilerilla y Aylácar (esta última hoy desaparecida, aunque identificable con el pago llamado Los Hilacares) se puede deducir que la iglesia fue construida en un espacio intermedio entre ambas aldeas, que estarían muy cercanas entre sí, apenas separadas por un arroyo (Fig. 3).

\section{LAS IGLESIAS DE PLANTA DE CAJÓN EN LA ALPUJARRA MUDÉJAR}

Introducción: el sistema de trabajo mudéjar La construcción de estas iglesias debe ser enmarcada en un contexto gremial, directamente relacionado con lo que se ha venido denominando «sistema de trabajo mudéjar $\rangle^{35}$. En el ámbito granadino, la arquitectura mudéjar representa en sus materiales una forma de trabajar concreta, directamente relacionada con el sistema de gremios y oficios medievales, profundamente reglamentada $\mathrm{y}$ con una fuerte estructura jerarquizada, que nos permite entender el porqué de la pervivencia de las técnicas medievales, aun en época moderna ${ }^{36}$. En el caso concreto de

\footnotetext{
31 Cressier 1983: 92-96.

32 Cressier identifica en Mecina Bombarón los siguientes barrios ya existentes en el siglo XVI: El Lauxar, Algayda, Abenyexen, Arrauda, Alozara, Abogayd, Ataraf, Abohidar, Haratamaera y los anejos de Golco y Montenegro (Cressier 1983: 94-95).

33 Trillo 2011: 78-79.

34 Hoy integrado en el de La Taha, cuya capital es Pitres.

35 Borrás 1986: 323-324.

36 Henares y López 1989: 59.
} 




Fig. 5: Vista general de la iglesia de Bayárcal y parcial del núcleo urbano. la Granada del siglo XVI, esta organización corporativa se halla regulada por las Ordenanzas Municipales, creando un corpus jurídico que reglamenta todas las actividades del taller. Así, mientras el maestro mayor o veedor se encarga de definir los modelos y del diseño y trazas de los nuevos proyectos eclesiásticos, serán los alarifes o maestros contratantes de la obra quienes den forma a dichos proyectos, encargándose del cálculo y acopio de materiales que harían falta para la consecución del proyecto.

\section{Tipología de plantas: la nave de cajón. Bayárcal, Capilerilla, Iniza, Júbar, Juviles, Tímar, Yátor}

El diseño de las plantas de estas iglesias las pone en relación directa con el plan de erección parroquial más arriba descrito, cuando ya a mediados del siglo XVI se desarrolla con más continuidad la construcción de iglesias de nueva planta que sustituyan los oratorios nazaríes. La relativa urgencia y la necesidad de acogerse a modelos perfectamente conocidos y fácilmente asimilables deriva en la elección, para la gran mayoría de nuevas parroquias, del modelo de nave única con testero plano y capilla mayor diferenciada según la entidad del proyecto: unas veces con una simple elevación del altar, otras con la construcción de un arco toral. Su amplia extensión e idoneidad queda reflejada en algunos testimonios escritos de la época, como en este fragmento de la carta que envía el deán de Almería al marqués de los Vélez, don Pedro Fajardo, el 12 de julio de 1512, indicando el modelo a seguir, referido en este caso a la iglesia de Vélez Blanco (Almería):

Que sea de una nave de treinta e tres pies de ancho e çiento e cinco de largo, de los quales a tener la capilla treinta e tres pies y el arco dos pies. El cuerpo de la iglesia sesenta pies. Han de ser las paredes de tres pies de grueso de mamposteria e tenga la iglesia treinta de alto. A de ser la armada de su armadura de pino, la capilla por sy ochavada e la iglesia por sy de su armadura de pino. Los tirantes que tengan medio pino de gordo e los estribos pino entero los pares, seys de un pino. E derribar la torre vieja que está fecha e fazerla junto con el flasçe del arco toral de manera que quede debaxo una capilla para pila de bautizar tejar la iglesia muy bien con sus alas de ladrillo, blanquear aquella de dentro e rebocalla de frente. Costará acabada la dicha yglesia dozientas e çinquenta mill mrs. ${ }^{37}$

El modelo descrito encaja a la perfección con la mayoría de las iglesias analizadas en este estudio. Se trata de una tipología de extrema sencillez que procede de las iglesias conventuales de planta única ${ }^{38}$, de las que ejemplos no faltan en la Alpujarra: Yátor, Juviles, Iniza, Benecid, Golco, Tímar, Padules, Bayárcal (Fig. 5), Bérchules, Mecina Fondales, etc. Y también podría hacerse extensivo a otras

\footnotetext{
37 Pérez 1995: 813.

38 Henares 1993: 23.
} 
regiones del recién conquistado Reino de Granada, como el Zenete o el Valle de Lecrín.

Concretando, las medidas de las naves de las iglesias estudiadas oscilan entre los aproximadamente 35 metros de largo por $10 \mathrm{~m}$ de ancho en el caso de Bayárcal, la más extensa de todas, y las iglesias de un tamaño menor, preparadas para albergar a los feligreses de lugares menos poblados, como los casos de Júbar o Iniza, ambas con similares medidas de cajón (19 x 8,5 m). Mención especial merece el caso de la iglesia de Tímar, cuyas medidas actuales son $17 \mathrm{~m}$ de largo por 9,5 de ancho, quedando una planta un tanto desproporcionada. Ello se debe a la evolución sufrida por el edificio, el cual tuvo problemas de cimentación desde el mismo comienzo de su construcción, en el primer tercio del siglo XVI. Sus medidas originales eran por entonces $24 \mathrm{~m}$ de largo por 9,5 m de ancho. Como decimos, su débil cimentación y el estar ubicada junto a un terraplén de escasa estabilidad, dan como resultado que pronto se den noticias de «quiebras que atraviesan la iglesia $»^{39}$, solucionándose a mediados del siglo XIX con la construcción una nueva fachada retranqueada $7 \mathrm{~m}$. Por último, quedan las iglesias de un tamaño intermedio, como serían Yátor $(24 \times 8,20 \mathrm{~m})$, Capilerilla (26 x $7 \mathrm{~m})$ o Juviles $(20 \times 8,80 \mathrm{~m})$. Atendiendo al texto antes incluido y a las medidas recogidas, se observa que en muchos casos los templos tienden hacia una proporción 1/3, aunque con claras oscilaciones (Fig. 6).

En la mayoría de los casos, estas iglesias presentarían una capilla mayor diferenciada del resto de la nave mediante un arco toral, como sería el caso de Juviles, Tímar, Yátor, Bayárcal (no conserva el arco pero sí las pilastras sobre las que apearía) y Capilerilla. La utilización de esta separación espacial en el interior de la iglesia conlleva una serie de adiciones sobre el proyecto básico de nave sencilla. Así, el arco toral expone a los paramentos a una solicitación transversal que requiere de unos contrafuertes exteriores que desempeñen la función de riostras para evitar la deformación de los muros. Estos contrafuertes están patentes en Tímar y Capilerilla, en donde la torre, ubicada en el lado de la Epístola, cumple las funciones mecánicas de riostra. También se observa cómo en algunos casos, la capilla mayor ha sido ampliada en alzado y a veces también en planta, aunque por sus características constructivas suele tratarse de modificaciones posteriores del proyecto original, como es apreciable en Juviles ${ }^{40}$.

\footnotetext{
39 Gómez-Moreno Calera 1989a: 381.

40 También podemos observar casos parecidos en otras iglesias cercanas, como Narila o Mairena.
}

El acceso a los templos se hacía mayoritariamente desde una portada lateral, siendo únicamente en la iglesia de Tímar donde hallamos un único acceso a los pies, aunque debemos recordar la reconstrucción total de la fachada de esta iglesia en el siglo XIX, por lo que no sería descartable un traslado del vano en este sentido. Por lo general, la puerta se ubica en el lado donde se ubica la torre, donde encontramos opciones variadas: lado de la Epístola para Iniza y Capilerilla, o la curiosa ubicación de la torre de la iglesia de Júbar, adosada al testero de los pies. Sin embargo, la opción más común observada es la de la ubicación de la torre en el lado del Evangelio, junto a la cabecera (Juviles, Bayárcal y Yátor). También existen los templos con portada a los pies y lateral, como es el caso de Juviles, Bayárcal y Yátor, aunque nos inclinamos a pensar que la portada de los pies de la última se trata de una obra posterior a tenor del reducido módulo de los ladrillos que presenta $(21,5$ x 11 x $3 \mathrm{~cm}$ ).

Esta composición del espacio mudéjar mediante nave rectangular y capilla mayor cuadrada diferenciada por un arco, se completará siempre con una carpintería de lo blanco. Por ejemplo, en Júbar la cubierta de la nave se resuelve con una armadura de limas moamares ochavada en la cabecera y tirantes apeinazados con lazo de ocho y diez sobre canes de tracería gótica. Es el único ejemplo de armadura ochavada que se conserva en la Alpujarra actualmente ${ }^{41}$, siendo lo más frecuente que dichas techumbres no hayan pervivido hasta nuestros días, salvo excepciones, siendo sustituidas generalmente por otras soluciones, como bóvedas de cañón y vaídas (Yátor) o carpinterías contemporáneas sin valor histórico (Bayárcal). No obstante, por motivos de espacio y temática preferimos dejar esta cuestión apartada.

\section{Técnicas constructivas}

Los materiales principales que componen la obra de estos templos son la piedra de cantería (mampostería y sillares) y el ladrillo.

\section{- Mampostería}

La fábrica esencial de los muros está realizada con mampostería. Los tamaños de los mampuestos varían según su utilización en el paramento, hallándose piezas careadas de gran volumen para la parte inferior, y de mediano y pequeño tamaño para el resto del alzado conservado. A excepción de estas piezas careadas de la

\footnotetext{
41 Jerez y Gómez 2006: 111-112.
} 


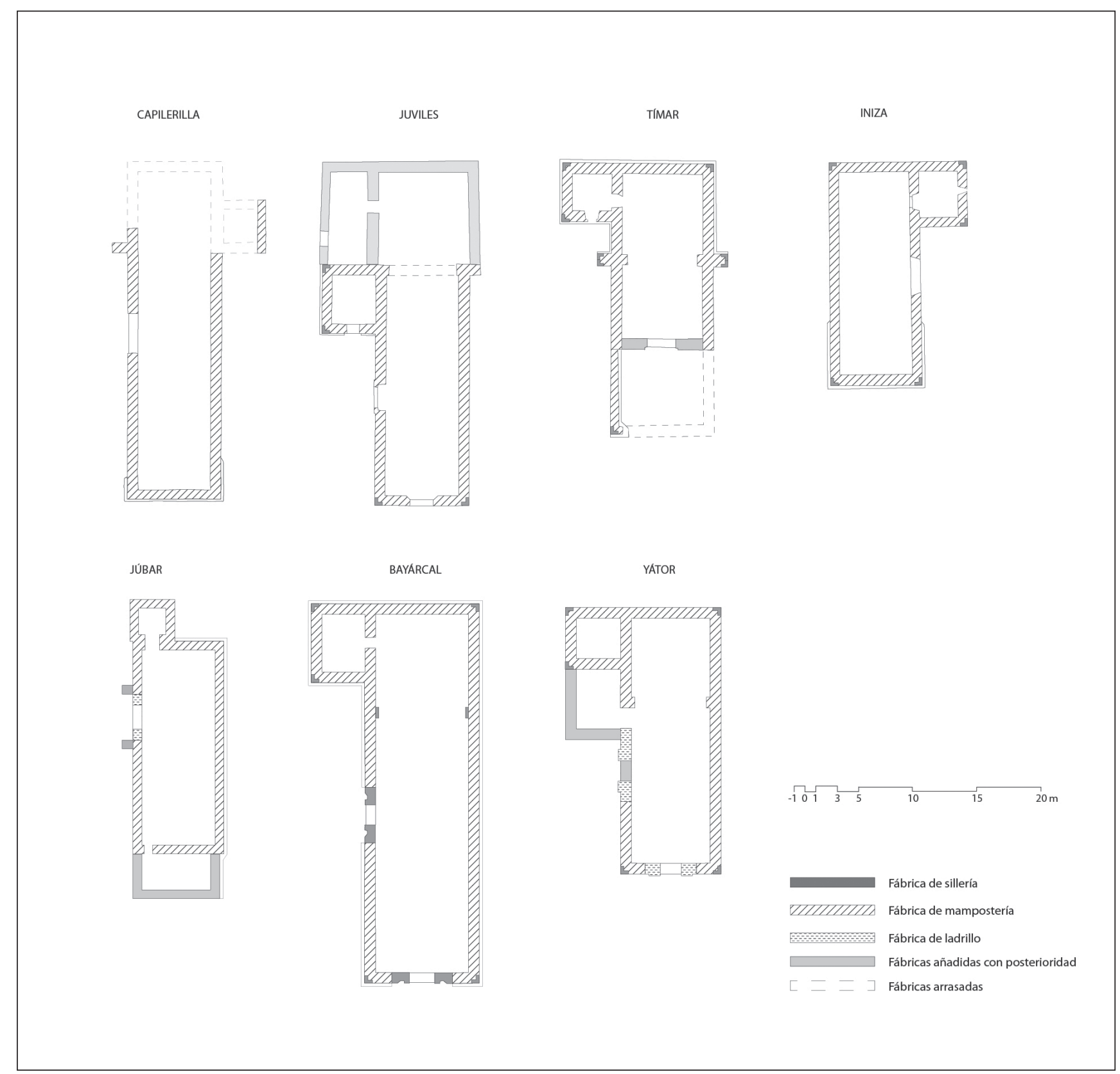

Fig. 6: Comparativa de las plantas de las iglesias estudiadas, con indicación de las técnicas constructivas principales y adiciones posteriores al proyecto original observadas en los paramentos exteriores. Juviles, Tímar e Iniza elaborado por los autores a partir de Cressier, 1988: 95-112. El resto elaboración propia.

base, la mampostería está poco trabajada, aunque sí que presenta algunas muestras de labra que permiten configurar hiladas horizontales más o menos regulares, combinado con el uso de ripios para el relleno de los intersticios, tomada la fábrica con un mortero de cal de gran dureza. La piedra utilizada con mayor asiduidad es el esquisto o falsa pizarra, autóctona y de fácil extracción (Bayárcal, Capilerilla) (Fig. 7), aunque también se encuentra la roca caliza combinada con la anterior (Iniza) (Fig. 8).
Un aspecto interesante documentado en algunos de los paramentos de las iglesias es el de su acabado exterior. En ciertos casos, se ha ejecutado un rejuntado completo del muro, convertido en un enfoscado total que presenta un llagueado en forma de vitola, como sería el caso de Iniza, o un esgrafiado sobre las líneas de contacto de los mampuestos, en Yátor (Fig. 9). También se realizan fingidos de sillería, como en la iglesia de Tímar (Fig. 10). 


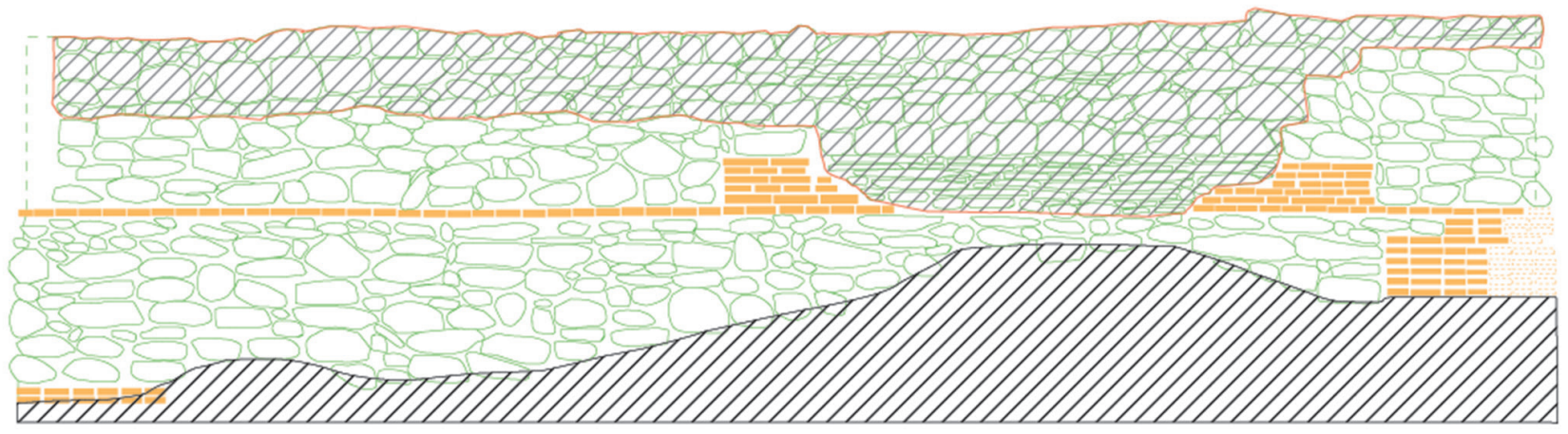

A



B

\section{WHITA Nivel de suelo actual}

\section{Fffff7 Reparaciones actuales}

Fábrica de ladrillo

Aristón de roca conglomerada

Mampostería de esquisto

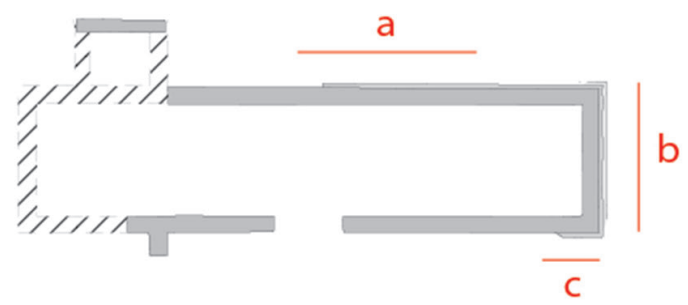

b

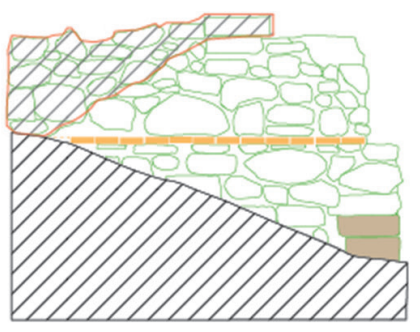

C

$0 \quad 1 \quad 2$
$5 m$

Fig. 7: Levantamiento de los paramentos conservados de la iglesia de Capilerilla. 


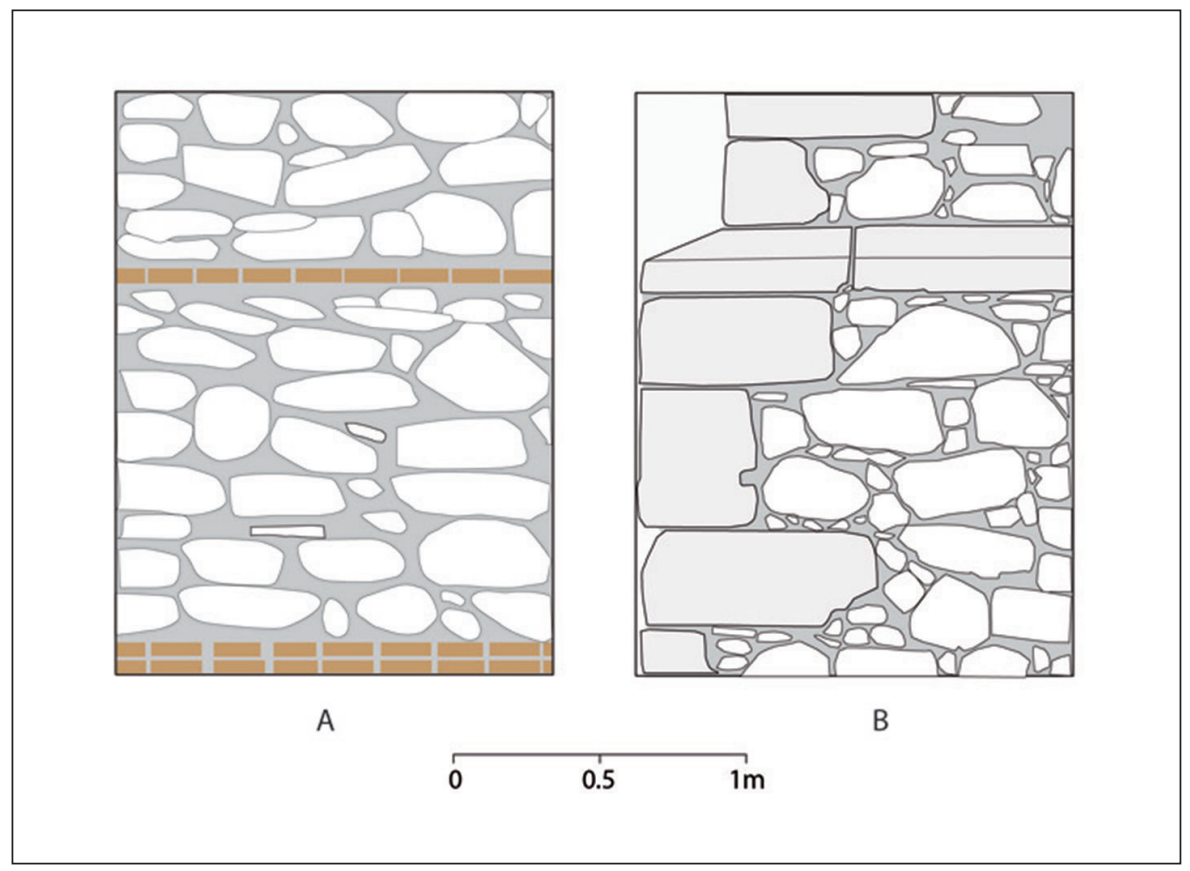

Fig. 8: Mampostería. Comparativa de paramentos: A - Capilerilla, con rafas de ladrillo. B - Iniza, con elementos de sillería (aristones y biseles).
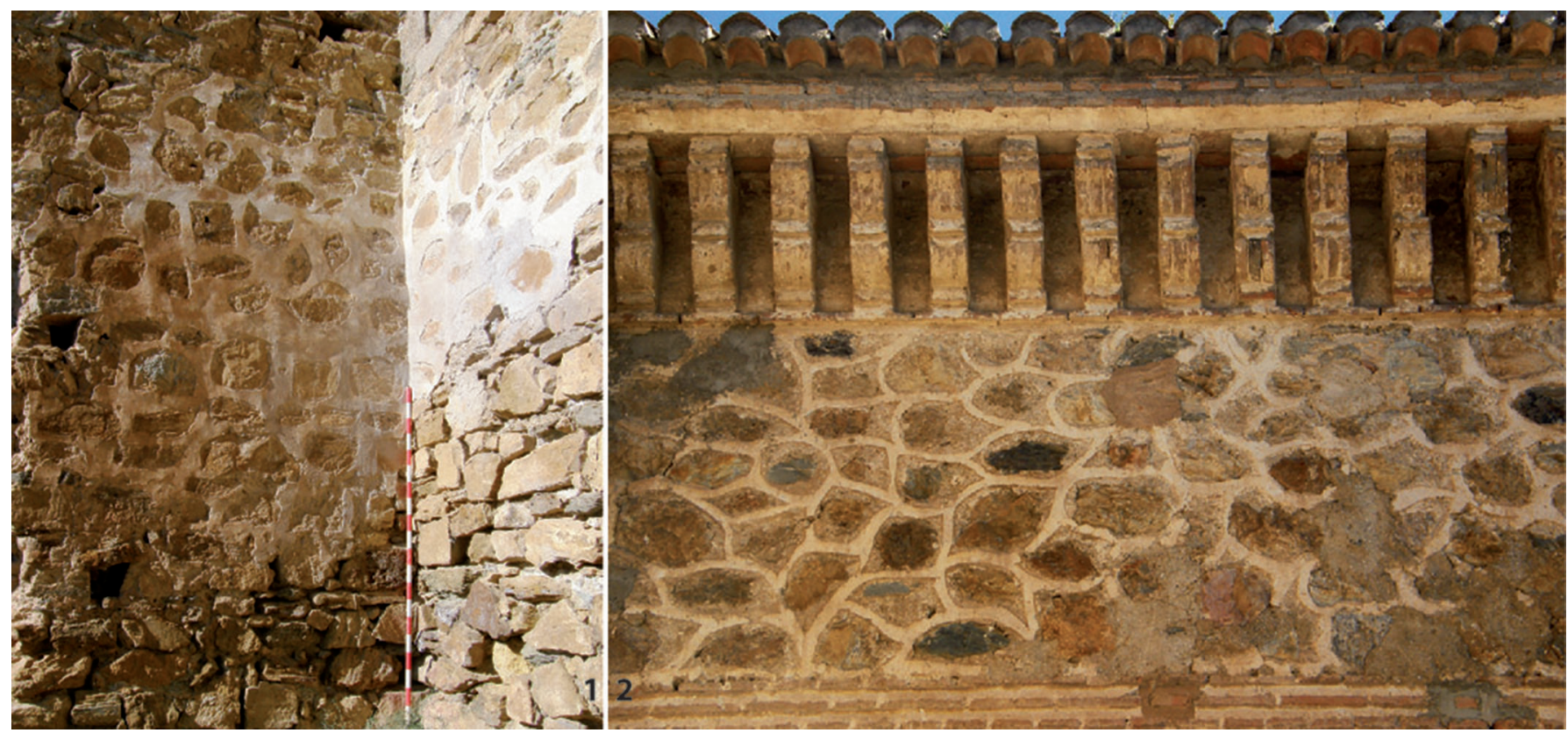

Fig. 9: Mampostería. Acabados exteriores con esgrafiados decorativos: 1 - Iniza. 2 - Yátor.

Una de las características más destacadas de estas iglesias son las zarpas. Estas marcan el final de los niveles de cimentación a través de un escalón, cuyo releje oscila entre 20 (Capilerilla) y $30 \mathrm{~cm}$ (Bayárcal, Júbar, Iniza), rematándose exteriormente con unas piezas de cantería biseladas. Este saledizo se situaría a $1 \mathrm{~m}$ de altura desde el primer nivel de cimentación en el caso de Capilerilla (fig. 7), pudiendo darse el caso de la gran zarpa de Bayárcal, que salva el importante desnivel en sus paramentos noroeste y suroeste con tres tramos de más de $2 \mathrm{~m}$ de altura cada uno.

\section{- Sillería}

La sillería será el otro gran protagonista en la fábrica de estos edificios. Esta hace referencia directa a un ciclo productivo de larga tradición y gran complejidad 


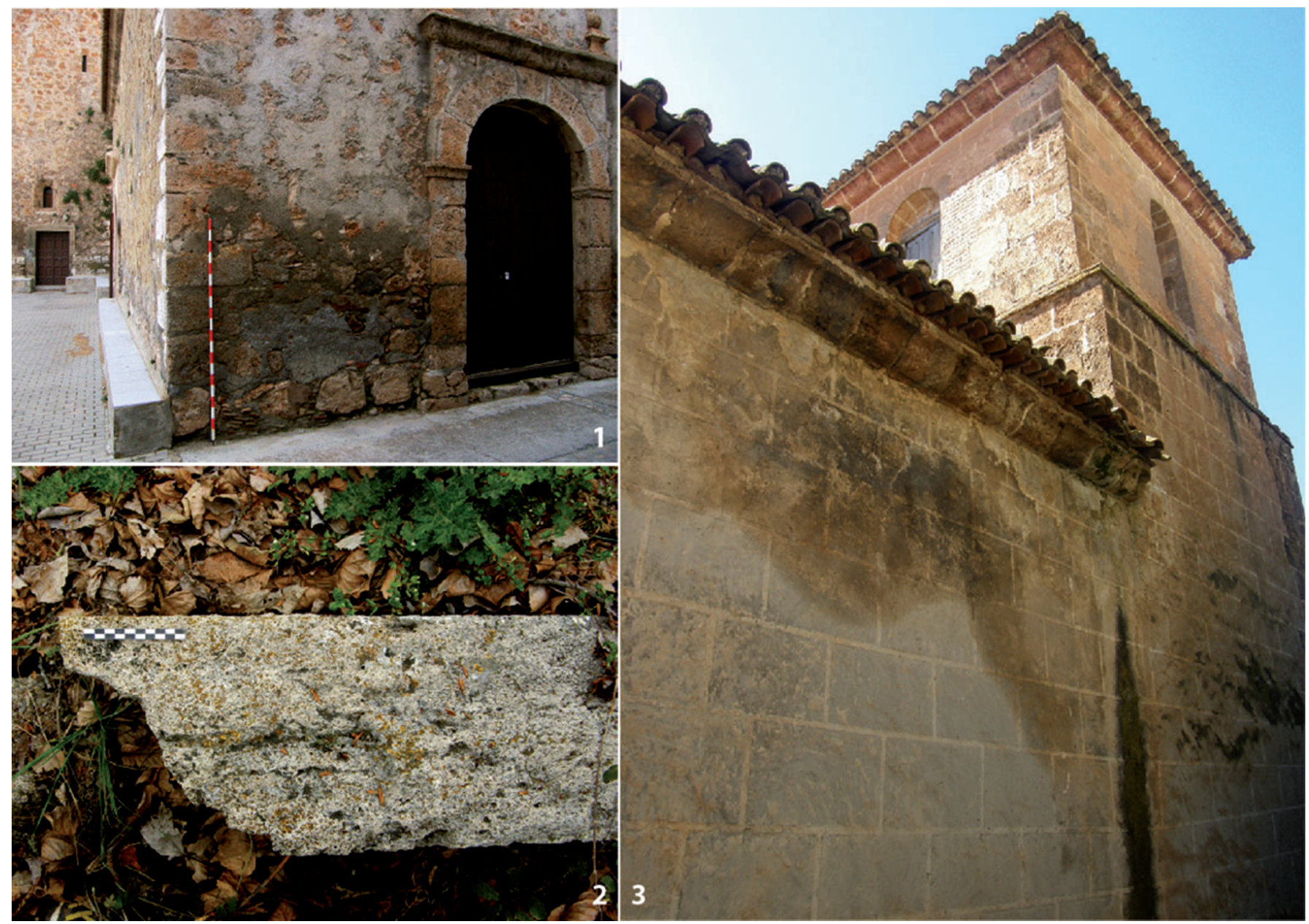

Fig. 10: Sillería. Aristones y cornisas: 1 - Aristones y portada de cantería de Juviles. 2 - Cornisa de perfil de gola reutilizada en la era de Capilerilla. 3 - Cornisa de Tímar.

que tendrá en la arquitectura mudéjar granadina un interesante papel. Numerosas familias de origen cántabro y vasco se encargarán de producir este material en el contexto de la erección parroquial del Reino recién tomado ${ }^{42}$, presentando un fuerte arraigo en el trabajo de este material y trasladando a Andalucía sus métodos y formas de organización gremial. En casos como el de muchas pequeñas iglesias alpujarreñas construidas en el siglo XVI, donde el trabajo de sillería ocupa sólo una parte concreta de la fábrica, será el alarife o maestro albañil el encargado de asentar estas piezas en la obra, lo cual nos habla del uso de las «técnicas de albañil $»^{43}$. En el caso concreto de esta región, más alejada de los grandes ciclos productivos de la capital, la cantería se transportaba ya directamente trabajada a pie de obra, donde el alarife se encargaría de buscar

42 Gómez-Moreno Calera 1989a: 57.

43 Quirós 1998: 236. su mejor adecuación sobre un material ya finalizado ${ }^{44}$. Se produce así una relación de los diferentes gremios (ladrilleros, yeseros, canteros, azulejeros, etc.), cuyo trabajo definitivo quedará en manos del alarife, erigido en un maestro albañil que llega a dominar los distintos aspectos que conforman la construcción de la iglesia.

La obra de sillería se reduce en estas iglesias a partes concretas (esquinas, puertas, ventanas, cornisas, etc.) requeridas de una mayor resistencia, pero también como parte del programa decorativo elegido. Uno de los casos más interesantes para el estudio de esta parte esencial se da en la iglesia de Capilerilla, la cual ha sufrido un dilatado expolio de los materiales más nobles de su fábrica, impidiendo precisar con más exactitud las características de la obra. No obstante, las piezas de sillería pueden ser rastreadas con relativa facilidad, dados sus volúmenes fácilmente reconocibles. Además, parte

\footnotetext{
44 Gómez-Moreno Calera 1989a: 61.
} 
de este expolio ha sido llevado a cabo por los mismos vecinos de la aldea, con el objetivo de rehacer balates, reconstruir muros, reparar sus viviendas y, sobre todo, en la construcción de una era anexa a la iglesia (Fig. 10). Se puede por ello distinguir distintas piezas según su funcionalidad y reconstruir una imagen aproximada de este templo. A ello se suma el estudio comparativo con otras iglesias, pudiendo constatar la existencia de elementos pétreos con la misma talla, aún conservados in situ en sus fábricas originales.

Así, tendríamos los sillares de esquina o aristones, una solución orientada a dotar al paramento de una mayor solidez en su fábrica. Dispuestos en cadena, presentan varios módulos, dentro del cual el más común hallado es el de $28 \times 28 \times 68 \mathrm{~cm}$. El uso de este material para las esquinas se puede documentar en una gran cantidad de iglesias alpujarreñas, sobre todo en aquellas realizadas en mampostería, y obviamente en los ejemplos analizados en este estudio (Juviles, Tímar, Yátor, Bayárcal o Iniza; Fig. 8).

De igual forma, aunque esta vez con un sentido no sólo funcional sino también estético, otras partes de estas iglesias recibirán un tratamiento más significativo a través del empleo de obra de sillería. Por ejemplo, las cornisas, donde hemos reconocido dos tipos de piezas similares, aunque de distinto módulo. Por una parte, las piezas con un lecho de $72 \mathrm{~cm}$ y un grosor de $52 \mathrm{~cm}$. Otra, de corte similar, varía en el lecho $(40 \mathrm{~cm})$, siendo su grosor coincidente con el ancho que los muros poseerían en la gran mayoría de estas iglesias $(95 \mathrm{~cm}$ aproximadamente). La altura es de $25 \mathrm{~cm}$, mostrando la cara vista una decoración de moldura con perfil de gola. Es una solución que va a aparecer en Tímar, Juviles, Capilerilla, Bayárcal e Iniza (Fig. 10).

Las ventanas (Fig. 11), por lo que suele ser común en la gran mayoría de los templos de esta zona, debieron ser escasas. Estos vanos estarían abocinados y así lo atestiguan las piezas de sillería halladas en la era de Capilerilla, donde documentamos una de las esquinas con una sección profunda que permitiría el cambio de luz desde el interior del paramento hacia el exterior, estando también documentadas en Yátor, Juviles, Tímar y en la ventana central (la original) de la portada de los pies de Bayárcal. Algunos de estos vanos, por su estrechez, se pueden calificar de saeteras (Yátor).

Una pieza ya antes mencionada serían las talladas a bisel, preparadas para rematar las zarpas (Figs. 8 y 11). Se trata de una solución que encontramos en Capilerilla, Juviles, Tímar, Iniza y Bayárcal, cuya soga puede llegar

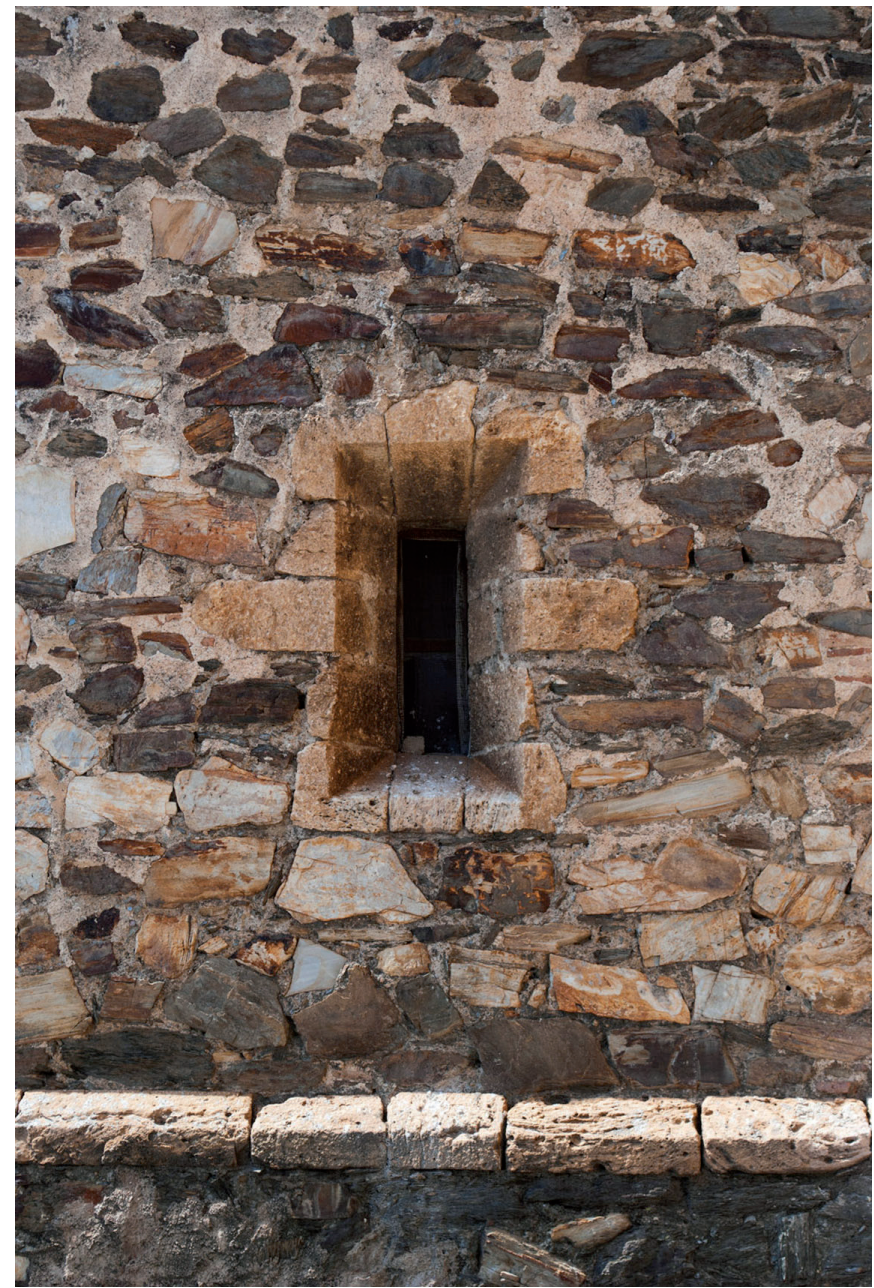

Fig. 11: Sillería. Ventana y biseles de Bayárcal.

a los $80 \mathrm{~cm}$, pero sin que aparezca un módulo claro y constante en los templos analizados.

Por último, queda referirnos a las portadas (Figs. 10 y 12). Las realizadas en cantería, presentan unas jambas de sillares con un pequeño rebaje en uno de sus laterales $(2 \mathrm{~cm})$ para adelantar la línea de portada con respecto de la fachada. La solución más común es la de un arco de medio punto enmarcado por una cornisa de perfil de gola, como vemos en Juviles (Fig. 10) y Bayárcal (Fig. 12). Sospechamos que también se dio este tipo para el templo de Capilerilla, a tenor de la aparición de algunas dovelas reaprovechadas en la aldea. Sobre la fachada de Tímar no es posible aseverar nada, al haber desaparecido la original, siendo la actual una obra relativamente reciente. Mención aparte merece Iniza, con portada en sillería, pero solucionada con arco escarzano (Fig. 12). Quedan para el siguiente apartado las de Yátor y Júbar, realizadas en ladrillo, muestra de la diversidad de soluciones utilizadas en una misma región. 


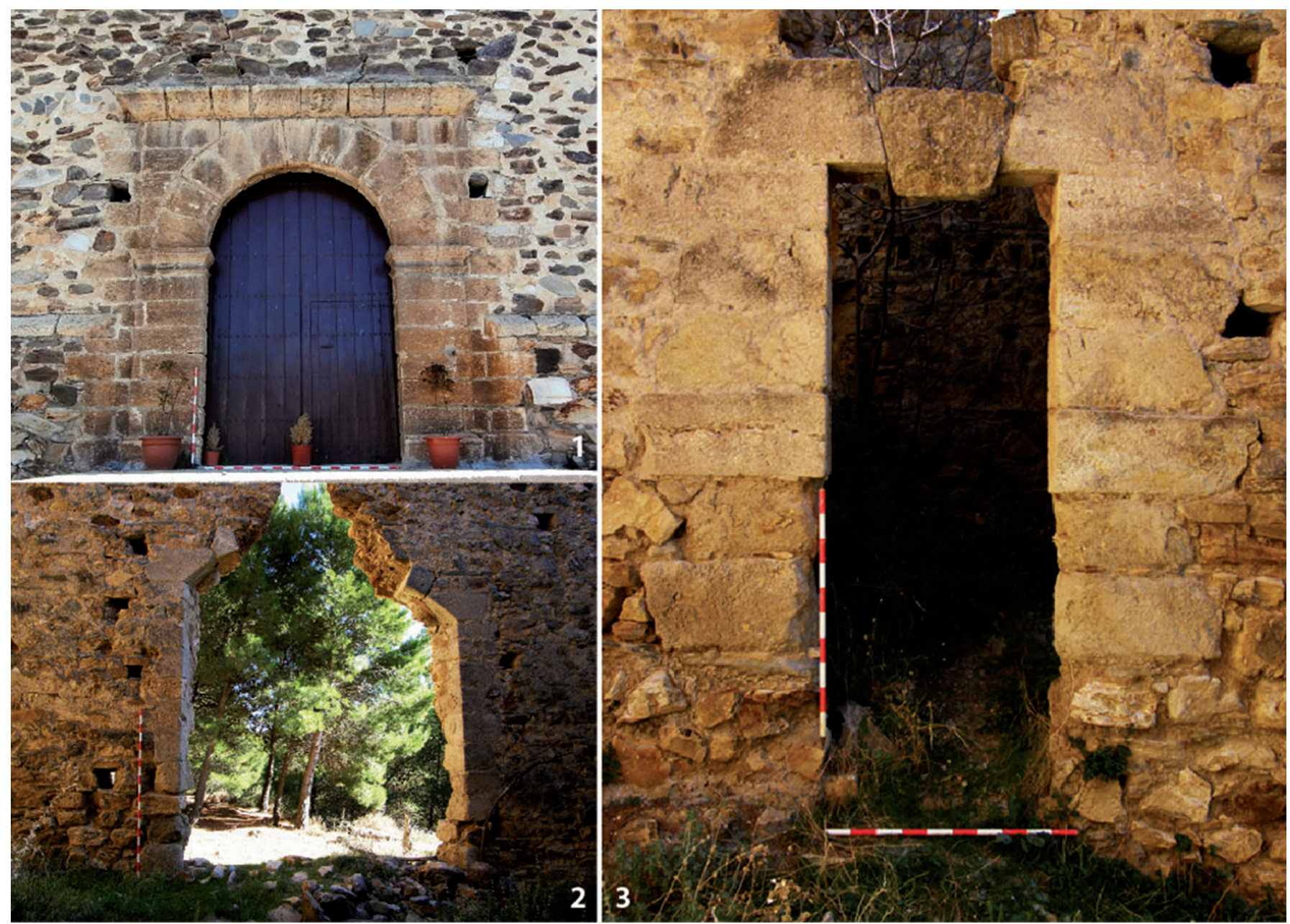

Fig. 12: Sillería. Portadas: 1 - Portada lateral de Bayárcal. 2 - Portada de Iniza, en arco escarzano. 3 - Puerta adintelada en Iniza.

\section{- Ladrillo}

Los módulos de los ladrillos documentados en algunas de las iglesias estudiadas dan unas proporciones similares, mayoritariamente entre los 28 y $32 \mathrm{~cm}$ de longitud, de 14 a $16 \mathrm{~cm}$ de anchura y con un grosor entre los 3,5 y los 6 $\mathrm{cm}$, como reflejamos en la siguiente tabla (Fig. 13).

Estas medidas coinciden esencialmente con los módulos de labor o común y es el utilizado en el trabajo de fábrica de los muros en el siglo XVI ${ }^{45}$. Se trata de un modelo que se tiene documentado en Andalucía Occidental desde el siglo XII ${ }^{46}$, presentando sus módulos a lo largo del tiempo mínimas diferencias, según la zona de aparición ${ }^{47}$. En síntesis, estos ladrillos poseen una medida muy similar a los módulos utilizados en arquitectura mudéjar

\footnotetext{
45 Gómez-Moreno Calera 1989a: 64

46 Graciani 2009: 128.

47 Para el área sevillana, el ladrillo mudéjar presenta unas medidas aproximadas de 28 x 14 x 4,5 cm (Graciani y Tabales 2008: 148). En Baza (Granada) los análisis puntuales efectuados sobre edificios modernos arrojan similares módulos (Montes, Alonso y Caballero 2010: 89-90).
}

en el sur de la Península en el siglo XVI, que arrojan una proporción $1 / 2$, de tradición almohade, y diferente de la proporción $2 / 3$, más normal en el área castellanatoledana ${ }^{48}$.

No es necesario mencionar las diversas posibilidades del ladrillo, en su uso no sólo constructivo, sino también como elemento decorativo, aunque en el caso de las iglesias analizadas sea un material que escasamente aparece (Capilerilla, Yátor y Júbar). Hemos observado en Capilerilla su utilización para remarcar la zarpa (figs. 7 y 8), conformando una base horizontal sólida sobre la que trabajar las fábricas de mampostería. En el caso del primer saledizo, se trata de una verdugada doble de ladrillos, cuya línea inferior se halla dispuesta a tizón y la superior a soga (aparejo inglés). Se juega con la posición del mismo y con los grosores del tendel, donde para el horizontal tenemos prácticamente el grueso de un ladrillo (4 $\mathrm{cm}$ aproximadamente) y prácticamente

\footnotetext{
48 Pavón 1986: 339; Caballero y Murillo 2004: 52.
} 


\begin{tabular}{|c|c|c|c|}
\hline Iglesia & Largo $(\mathrm{cm})$ & Ancho $(\mathrm{cm})$ & Grosor $(\mathrm{cm})$ \\
\hline $\begin{array}{c}\text { Yátor } \\
\text { (portada lateral) }\end{array}$ & 32 & 16 & 6 \\
\hline Capilerilla & 29,5 & 15 & 4,5 \\
\hline Júbar & 28 & 14 & 3,5 \\
\hline
\end{tabular}

Fig. 13: Medidas de los ladrillos analizados.
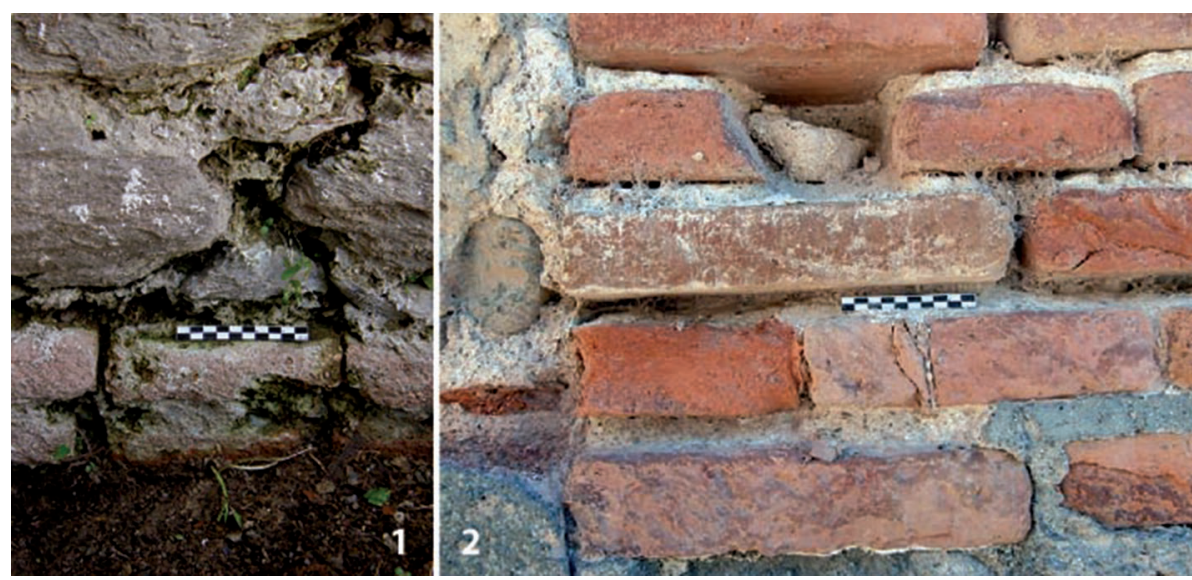

Fig. 14: Ladrillo: 1 - Capilerilla. 2 - Yátor (portada lateral).

nulo ( $1 \mathrm{~cm}$ como máximo) para la llaga vertical, conformándose una perspectiva del edificio con tendencia a la horizontalidad (Fig. 14).

También hay que destacar la utilización de pequeñas rafas de ladrillo en el eje central del muro lateral oriental de Capilerilla, donde parece finalizar el saledizo inferior, salvándose con ello el desnivel existente entre la cabecera y los pies (Fig. 7). Estas cajas se hallan muy afectadas por el proceso de desmonte del edificio efectuado a mediados del siglo XX, perjudicando sensiblemente su conservación e impidiendo en gran medida su comprensión. Se han conservado 6 hiladas de altura de caja, por 2 sogas aproximadamente para su ancho. Este indicio podría indicarnos el uso de una técnica mixta de rafas de ladrillo y cajas de mampostería (aparejo toledano), combinada con la mampostería para el resto de las fábricas. Con todo, nos movemos únicamente en el terreno de la hipótesis dada la imposibilidad actual de completar el análisis en un paramento tan deteriorado.

En otras iglesias se emplea el ladrillo fundamentalmente para las portadas y el alzado de los últimos cuerpos de las torres-campanario. Entre las portadas, destaca la de Júbar (Fig. 15), en el lateral oeste y realizada íntegramente en ladrillo, cuyas piezas presentan un módulo de $28 \mathrm{x}$ $14 \times 3,5 \mathrm{~cm}$. Se compone mediante un arco ligeramente apuntado, enmarcado en alfiz, de estética tendente al gótico-mudéjar. Las jambas aparecen muy erosionadas bajo la línea de impostas. A ambos lados de esta portada se han adosado sendos contrafuertes ataludados, constituyendo un añadido del siglo XIX. Los demás paramentos están hoy en día completamente enlucidos de modo que es imposible hacer una lectura de los mismos. No obstante, en el muro posterior de la sacristía, que da al cementerio, sí se aprecia que está realizado en ladrillo con cajones de mampostería (aparejo toledano), aunque de ello no podemos deducir que el resto de la iglesia haya sido construida con el mismo aparejo.

Este apartado no hace sino resaltar la gran variedad de soluciones adoptadas en la elaboración material de las iglesias alpujarreñas en el siglo $\mathrm{XVI}^{49}$. En el caso del ladrillo, su aparición es bastante común no sólo por

\footnotetext{
49 El estudio mensiocronológico de ladrillos utilizados en arquitectura mudéjar en un contexto general está representado en algún trabajo clásico (Pavón 1986: 329-364), aunque se hace necesario el desarrollo de una línea de estudio más orientada a la investigación en un ámbito local. En nuestro caso, la necesidad de afrontar un acercamiento a este tipo material con una metodología que incluya paralelos tomados en otras iglesias cercanas cronológica y geográficamente se presenta como una labor esencial, pero compleja. La procedencia de los ladrillos no es clara y, en la mayoría de ocasiones, se muestra como un material extraño y casi inexistente en muchas de las iglesias alpujarreñas estudiadas. Por poner un ejemplo, los casos de Iniza, Bayárcal y Juviles, presentan una total ausencia de material latericio en sus fábricas, o con alguna presencia más relacionada con reparaciones contemporáneas o ampliaciones efectuadas en momentos posteriores.
} 


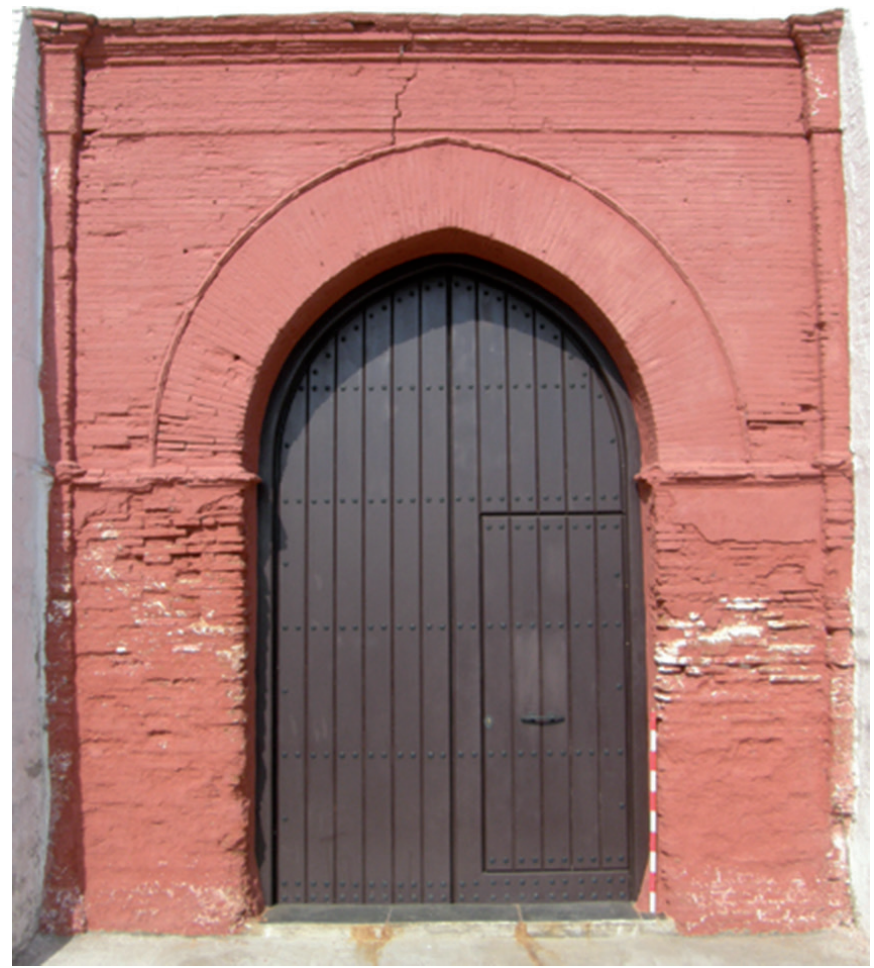

Fig. 15: Ladrillo. Portada de Júbar.

su versatilidad constructiva, solución de economía o las posibilidades decorativas que permite, sino también como sistema de medida para la ejecución de la obra ${ }^{50}$, revelándose como el material sobre el que se calculan las dimensiones de la obra.

\section{CONCLUSIONES}

Con los datos recabados desde las líneas de trabajo presentadas en este artículo, hemos podido conceptualizar un conjunto de edificios como iglesias mudéjares de nave única o de cajón, realizando un análisis de plantas, técnicas constructivas, materiales y, en parte, el urbanismo que lo acoge y en el que encuentra sentido. Para ello se han conjugado las herramientas metodológicas de la Arqueología de la Arquitectura y de la Historia del $\mathrm{Arte}^{51}$, generando un diálogo entre ambas disciplinas que ha conducido a caracterizar una serie de edificios religiosos mudéjares surgidos en un contexto rural en un momento de alta conflictividad sociocultural, como es la Alpujarra en el siglo XVI.

En la Granada del quinientos se van a dar cita varios lenguajes arquitectónicos: uno heredado de la capital del

\footnotetext{
50 Lavado 2010: 340.

51 Arce 2009: 28
}

reino nazarí, prácticamente intacta en su configuración y edificación; otro presente en la tradición figurativa y productiva gremial medieval, que va a dar forma a los programas constructivos oficiales y eclesiásticos más importantes de la primera época; y otro en proceso de asimilación, el clasicista, más acorde a la imagen de ciudad imperial ideada por Carlos V. En una situación intermedia, la arquitectura mudéjar se revela como una posibilidad integradora en una ciudad con dos realidades radicalmente ajenas y en conflicto: la cristiana y la morisca ${ }^{52}$. Frente a los lenguajes constructivos y estéticos elegidos para la construcción de los grandes proyectos de la Corona y el arzobispado, más ligados a los estilos internacionales góticos y clasicistas, para la dotación parroquial de la ciudad recién tomada y de los ámbitos rurales del Reino de Granada se adopta el mudéjar como principal opción, ante la situación de urgencia surgida, siendo asimilado por su bajo coste, la versatilidad constructiva relacionada con las posibilidades de contratación de mano de obra cristiana o morisca (o ambas) y, sobre todo, por la búsqueda de un lenguaje estético común que permitiera tanto consolidar la religión cristiana como aglutinar al infiel desde una postura proselitista $^{53}$.

Si nos desplazamos a la Alpujarra, en el marco ya visto de desigual desarrollo del plan parroquial, cualquiera de las iglesias estudiadas, aún en su estado de ruina o abandono de algunas de ellas, puede revelarse como un ejemplo de implantación de la Iglesia en un ámbito rural morisco, adquiriéndose el «espacio mudéjar» como opción oficial aglutinadora de la experiencia granadina. La elección de una planta sencilla de origen bajomedieval, de nave única con capilla mayor diferenciada mediante arco toral y testero plano; la presencia perfectamente rastreable del sistema de trabajo mudéjar, organizado en gremios, definiéndose como un sistema operativo y bien definido y siempre encabezado por la figura del alarife; la elección de un sistema de cubiertas con una gran carpintería de lo blanco en una clara asimilación del lenguaje decorativo nazarí, o los trabajos de sillería que son sintomáticos de los nuevos lenguajes clásicos que ya se imponen: todo ello se da cita en este programa arquitectónico que va a conformar el particular espacio mudéjar granadino, y del que estas iglesias son una pequeña muestra dentro del enorme y particular solar alpujarreño.

\footnotetext{
52 Orozco 1985: 73.

53 Díez 2001: 317.
} 


\section{Agradecimientos y ficha técnica}

Este trabajo se ha hecho dentro del proyecto de investigación «La arquitectura residencial de al-Andalus: análisis tipológico, contexto urbano y sociológico. Bases para la intervención patrimonial» (HAR2011-29963), cuyo investigador principal es Julio Navarro Palazón (Escuela de Estudios Árabes, CSIC). Forma parte del Plan Nacional de I+D + i y se enmarca en el VI Plan Nacional de Investigación Científica, Desarrollo e Innovación Tecnológica 2008-2011.

Las figuras son elaboración propia de los autores, salvo indicación de otra fuente en el pie. Todas las fotografías han sido realizadas por los autores.

Los autores desean agradecer la colaboración prestada por diversas personas e instituciones, entre ellos el equipo arqueológico del Ilmo. Ayuntamiento de Estepona (Málaga), el Ayuntamiento de Nevada (Granada) y numerosos vecinos de las poblaciones de la Alpujarra. También nuestro reconocimiento a Javier Sánchez Real y Alberto Martín Quirantes, por su desinteresada colaboración, en la cesión de información documental y fotográfica, y a quienes también ayudaron para llevar a cabo este trabajo: M. ${ }^{a}$ Nieves Bravo Gómez y Esther Carrero Fernández.

\section{Bibliografía}

Arce Sainz, F. 2009: "Historia de Arte, Arqueología de la Arquitectura y el telescopio de Galileo", Arqueología de la Arquitectura, 6, pp. 21-29.

Borrás Gualís, G. 1986: "Los materiales, las técnicas artísticas y el sistema de trabajo, como criterios para la definición del arte mudéjar", en Actas del III Simposio Internacional de Mudejarismo, pp. 317-325. Instituto de Estudios Turolenses, Teruel.

Caballero Zoreda, L. y Murillo Fragero, J.I. 2004: “Cómo se construye una torre mudéjar. La torre de San Pedro el Viejo de Madrid", Arqueología de la Arquitectura, 3, pp. 39-60. [En línea] http://arqarqt.revistas.csic.es/ index.php/arqarqt/article/view/60 [Consultado el 30/09/2014]

Carrascosa Salas, J.M. 1960: A las puertas de la Alpujarra. Diputación Provincial de Granada, Granada.

Cressier, P. 1983: "L'Alpujarra médiévale: une approche archéologique", Mélanges de la Casa de Velázquez, XX, pp. 89-124.

Cressier, P. 1988: "Églises et châteaux dans l'Alpujarra a la fin du moyen âge: 1'implantation d'un pouvoir", en Actas del encuentro hispano-francés sobre Sierra Nevada: la historia, la tierra y el poblamiento de Sierra Nevada y su entorno, pp. 95-112. Casa de Velázquez y Universidad de Granada, Granada.

Díez Jorge, M.E. 2001: El arte mudéjar: expresión estética de una convivencia. Universidad de Granada e Instituto de Estudios Turolenses, Granada.

Epalza, M. de 1996: "Mutaciones urbanísticas debidas a la transformación de mezquitas en iglesias", en Actas del IV Simposio Internacional de Mudejarismo, PP. 501-518. Instituto de Estudios Turolenses, Teruel.

Espinar Moreno, M. y Quesada Gómez, J. 1995: "Mezquitas convertidas en iglesias en las comarcas de Guadix y Baza (1490-1501). Datos sobre el urbanismo mudéjar", en Actas del VI Simposio Internacional de Mudejarismo, pp. 767-788. Instituto de Estudios Turolenses, Teruel.

Galán Sánchez, Á. 1991: Los mudéjares del Reino de Granada. Universidad de Granada, Granada.
Gómez-Moreno, M. 1951: "De la Alpujarra", Al-Andalus, 16/1, pp. 17-36. Gómez-Moreno Calera, J.M. 1987: "La visita a las Alpujarras de 1578-1579: estado de sus iglesias y población”, en Homenaje al profesor Dario Cabanelas Rodríguez, vol. 2, pp. 355-367. Universidad de Granada-Departamento de Estudios Semíticos, Granada.

Gómez-Moreno Calera, J.M. 1989a: La arquitectura religiosa granadina en la crisis del Renacimiento (1560-1650). Diputación Provincial de Granada, Granada.

Gómez-Moreno Calera, J.M. 1989b: "Las primeras iglesias construidas en las Alpujarras. Aportación documental”, Cuadernos de Arte de la Universidad de Granada, 20, pp. 189-192.

Gómez-Moreno Calera, J.M. 2004: “Arte y marginación. Las iglesias de Granada a fines del siglo XVI”, en V. Sánchez y J. Ruiz (coords.), III Jornadas de Religiosidad Popular, pp. 291-312. Instituto de Estudios Almerienses, Almería.

Graciani García, A. 2009: "La técnica del tapial en Andalucía occidental", en Á. Suárez Márquez (coord.), Construir en al-Andalus. Actas de las Jornadas Técnicas del Conjunto Monumental de la Alcazaba, pp. 111-140. Consejería de Cultura de la Junta de Andalucía, Almería.

Graciani García, A. y Tabales Rodríguez, M.Á. 2008: "El tapial en el área sevillana. Avance cronotipológico estructural", Arqueología de la Arquitectura, 5, pp. 135-158.

Henares Cuéllar, I. 1993: "La arquitectura mudéjar después de la conquista de Granada. Un modelo de organización espacial, productiva y simbólica", en I. Henares Cuéllar y R. López Guzmán (coords.), Mudéjar Iberoamericano. Una expresión cultural de dos mundos, pp. 21-37. Universidad de Granada, Granada.

Henares Cuéllar, I. y López Guzmán, R. 1989: Arquitectura mudéjar granadina. Caja Granada, Granada.

Jerez Hernández, J.M. y Gómez Peláez, M.A. 2006: Nevada, de las cumbres al valle. Ayuntamiento de Nevada, Laroles.

Lavado Paradinas, P. 2010: "Espacio y símbolo en la arquitectura y urbanismo mudéjares", en G. Borrás Gualís (coord.), Mudéjar. Legado andalusi en la cultura española, pp. 338-358. Universidad de Zaragoza, Zaragoza.

López de Vargas Machuca, T. 1990: Diccionario Geográfico de Andalucía: Granada. Editorial Don Quijote, Granada.

Martínez Ruíz, J. 1985: "El topónimo hara en las tahas de Ferreyra, Poqueyra y Xubiles en 1527”, en Philologica hispaniensia in honorem Manuel Alvar, vol. 2, pp. 481-494. Editorial Gredos, Madrid.

Montes Rivas, A., Alonso Ruiz, M. y Caballero Cobos, A. 2010: "Intervención arqueológica en la Alhóndiga de Baza. Arquitectura y urbanismo en el centro histórico de la Baza moderna", Péndulo, 11, pp. 79-104.

Navarro Palazón, J. y Jiménez Castillo, P. 2007: Las ciudades de Alandalús. Nuevas perspectivas. Instituto de Estudios Islámicos y del Oriente Próximo, Zaragoza.

Orozco Pardo, J.L. 1985: Christianópolis. Urbanismo y Contrarreforma en la Granada del Seiscientos. Diputación Provincial de Granada, Granada.

Pavón Maldonado, B. 1986: "Hacia un tratado de arquitectura de ladrillo árabe y mudéjar", en Actas del III Simposio Internacional de Mudejarismo, pp. 329-364. Instituto de Estudios Turolenses, Teruel.

Pérez Boyero, E. 1995: "La construcción de las iglesias en el marquesado de los Vélez", en Actas del VI Simposio Internacional de Mudejarismo, pp. 811-831. Instituto de Estudios Turolenses, Teruel.

Quirós Castillo, J.A. 1998: "La sillería y las técnicas constructivas medievales: historia social y técnica de la producción arquitectónica”, Archeologia Medievale, 25, pp. 235-246.

Sánchez Real, J. 2000: "La arquitectura religiosa de Las Alpujarras: un patrimonio poco conocido", en Actas de las las Jornadas de Patrimonio Histórico de la Alpujarra. Legado Arquitectónico y Patrimonio Rural, pp. 61-98. Centro Virgitano de Estudios Históricos de Berja, Almería.

Sánchez Zufiaurre, L. 2007: Técnicas constructivas medievales: nuevos documentos arqueológicos para el estudio de la Alta Edad Media en Álava. Servicio Central de Publicaciones del Gobierno Vasco y Servicio Editorial de la Universidad del País Vasco, Vitoria-Gasteiz y Leioa.

Spahni, J.C. 2010: La Alpujarra, la Andalucía secreta. Editorial Comares, Granada. 
Suberbiola Martínez, J. 1987: "La erección parroquial granatense de 1501 y el reformismo cisneriano", Cuadernos de Estudios Medievales, XIV-XV, pp. 115-144.

Téllez Sánchez, V. 2003: Al sur de Ronda. Historia, descripción e inventario del patrimonio histórico-artístico de los valles del Genal y Guadiaro. Editorial La Serranía, Ronda.

Trillo San José, C. 1990: "La Ta'a de Andarax después de la Conquista”, en AA.VV., Almería entre culturas: (siglos XIII-XVI), pp. 415-430. Instituto de Estudios Almerienses, Almería.
Trillo San José, C. 1992: La Alpujarra. Historia, Arqueología y Paisaje. Diputación Provincial de Granada, Granada.

Trillo San José, C. 2011: "Mezquitas en al-Andalus: un espacio entre las comunidades y el poder", Studia Historica. Historia Medieval, 29, pp. 73-98. 